University of South Florida

DIGITAL COMMONS

Digital Commons @ University of

@ UNIVERSITY OF SOUTH FLORIDA

South Florida

KIP Articles

KIP Research Publications

January 2012

\title{
An electrical resistivity imaging-based strategy to enable site- scale planning over covered palaeokarst features in the Tournaisis area (Belgium)
}

Olivier Kaufmann

John Deceuster

Yves Quinif

Follow this and additional works at: https://digitalcommons.usf.edu/kip_articles

\section{Recommended Citation}

Kaufmann, Olivier; Deceuster, John; and Quinif, Yves, "An electrical resistivity imaging-based strategy to enable site-scale planning over covered palaeokarst features in the Tournaisis area (Belgium)" (2012). KIP Articles. 5764.

https://digitalcommons.usf.edu/kip_articles/5764

This Article is brought to you for free and open access by the KIP Research Publications at Digital Commons @ University of South Florida. It has been accepted for inclusion in KIP Articles by an authorized administrator of Digital Commons @ University of South Florida. For more information, please contact digitalcommons@usf.edu. 


\title{
An electrical resistivity imaging-based strategy to enable site-scale planning over covered palaeokarst features in the Tournaisis area (Belgium)
}

\author{
Olivier Kaufmann *, John Deceuster, Yves Quinif \\ University of Mons, Faculty of Engineering, Fundamental and Applied Geology, 9 rue de Houdain, 7000 Mons, Belgium
}

\section{A R T I C L E I N F O}

\section{Article history:}

Received 10 November 2011

Received in revised form 26 January 2012

Accepted 28 January 2012

Available online 18 February 2012

\section{Keywords:}

Karst

Sinkhole

Resistivity tomography

Site-scale planning

Site characterization

Cone penetration tests

\begin{abstract}
A B S T R A C T
Since the beginning of the 20th century, more than 150 sinkhole occurrences, mainly dropout (or covercollapse) sinkholes, have been reported in the Tournaisis area (south-eastern Belgium). Land-use planning in such a context has to take into account hazards linked with sinkhole subsidence and collapse. Management maps, drawn at a regional scale, point out zones where karstic risks have to be taken into account when dealing with infrastructure or building projects. However, karst hazard is highly variable in three dimensions at the local scale. Therefore, for such purposes, an accurate methodology is needed to detect and delineate covered karst features, especially when located in urbanized areas.

As geophysical investigations are sensitive to contrasts in physical properties of soils, these methods can be useful to detect such targets. The specific karstic context encountered in the Tournaisis area strongly guides the choice of investigation techniques. Electrical resistivity imaging (ERI) methods were tested on a wellknown site where dropout sinkholes occurred formerly. This site was also studied using static cone penetration tests (CPT) and boreholes. A 3D inverted resistivity model was computed based on the 2D ERI models obtained after inversion. Resistivity profiles were extracted at each CPT location and compared to geotechnical results to determine an empirical and site-specific resistivity law that allows discrimination between weathered zones and sound limestone. Performance tests were conducted to evaluate the potential of the proposed methodology for two typical engineering problems based on two current hypotheses. Borehole data were used as ground truth. Similar performance tests were also computed using the CPT depth to bedrock model. The results of these performance tests are compared and discussed. Finally, an ERI-based investigation strategy is proposed to assess karst hazard in palaeokarstic context, such as encountered in the Tournaisis area, at the scale needed for building and infrastructure purposes.
\end{abstract}

(c) 2012 Elsevier B.V. All rights reserved.

\section{Introduction}

Land-use planning in covered karst terrains should take into account hazards linked with sinkhole activity. Covered karst areas are characterized by soluble rocks overlain by residual soils or allogenic sediments. Due to the presence of these cover materials, typical karstic landforms may be concealed. The presence of karst may remain unknown when sinkhole collapses do not reach the surface. When occurring in urbanized areas, these collapses can cause considerable damage on buildings and infrastructure ranging from temporary loss of serviceability during repair works to complete destruction and loss of human lives. Well-known cases of such damage have been reported all around the world. Examples of severe damage due to sinkhole activity can be found in: Sowers, 1996 (Winter Park, Florida, USA), Dougherty, 2005 (Allentown Corporate Plaza in Pennsylvania, USA), Buchignani et al., 2008 (Camaiore city in Tuscany, Italy),

\footnotetext{
* Corresponding author. Tel.: + 32653746 21; fax: + 3265374610 .

E-mail addresses: olivier.kaufmann@umons.ac.be (O. Kaufmann), john.deceuster@umons.ac.be (J. Deceuster),yves.quinif@umons.ac.be (Y. Quinif).
}

Buttrick and van Schalkwyk, 1998 (Gauteng Province in South Africa) and Yuan et al., 1998 (southern China).

At a regional scale, integrated methodologies have been developed to assess karst hazards (Edmonds et al., 1987; Kaufmann and Quinif, 2002; Benson et al., 2003; Waltham et al., 2005; Caramanna et al., 2008; Cooper, 2008; Galve et al., 2009). According to Waltham et al. (2005), the first step usually involves collecting records of sinkhole occurrences and other karst features and storing them in a database to produce a danger map which is an inventory map that shows the locations of mapped sinkholes and provide information on size, age and other relevant parameters. This danger map corresponds to the second level of hazard mapping in sinkhole terrains as defined by Waltham et al. (2005). To produce a hazard map, locations of recorded features are analyzed. Relevant background knowledge such as the geological and hydrogeological context should be taken into account in this analysis. Hazard levels are then defined and hazard maps are drawn. These maps may be computed within a GIS system (e.g. Kaufmann and Quinif, 2002; Cooper, 2008; Galve et al., 2009). Given the expected consequences of sinkholes, hazard maps can be combined with land-use maps to evaluate 
risks associated with different land uses. Finally, management maps may be derived from the risk maps to prevent and control development where needed.

However, these maps are usually drawn at a regional scale, typically tens of squared kilometers, while karstic hazard is highly variable in space at a local scale, typically from a few areas to a hectare. That is why local analysis for building purposes needs to be carried out at the local scale. When the presence of karst features cannot be predicted from surface evidence, as in covered karst areas, specific methodologies are needed to develop three dimensional engineering geological models of the near surface.

Geotechnical investigations, such as destructive boreholes or cone penetration tests have been shown to have limitations in the detection of such targets (Thomas and Roth, 1999). Indeed, the three dimensional geometry of karst features is often complex. Moreover, the depth of penetration could be limited by competent cover materials such as marls or chalk. Though these direct investigations are required to precisely determine the nature of the soils and to estimate soil resistance, they give only single point data. The number of boreholes and/or CPTs needed to reliably map buried karst features or detect sinkholes infilled to the surface rises quickly with the site dimension, as well as the cost of such investigations. Therefore, in practice, the number of geotechnical tests is limited and the reliability of interpretations based only on such investigations tends to be poor (Thomas and Roth, 1999).

Even if karstic terrains remain a challenging context for geophysical investigations, continuous development of acquisition and processing techniques have significantly improved their imaging abilities (e.g., Aizebeokhai (2010), Loke and Barker (1996b)). Moreover, they are minimally intrusive and may prove cost-effective (Reynolds, 2011). That is why these imaging techniques are of increasing interest to improve the knowledge of ground conditions. Indeed, geophysical methods allow the detection of contrasts in physical properties of soils, such as density, magnetic susceptibility, dielectric constant or electrical resistivity. Geophysical surveys have been conducted in karst terrains to map karst hazards such as voids, conduits, sinkholes and weathered zones for several decades. Most of the techniques used were developed to detect water-, air- or sediment-filled cavities as some of their physical properties may be significantly different from those of the host bedrock. The methods tested include magnetometry (e.g. Gibson et al., 2004; Rybakov et al. , 2005; Mochales et al., 2007, 2008; Pueyo-Anchuela et al., 2010), ground penetrating radar (e.g. Beres et al., 2001; Al-fares et al., 2002; Mochales et al., 2008; PueyoAnchuela et al., 2010), seismic reflection (Cook, 1965), surface wave analysis (Thierry et al., 2005), micro-gravimetry (e.g. Bishop et al., 1997; Beres et al., 2001; Rybakov et al., 2001; Thierry et al., 2005; Mochales et al., 2008) and DC resistivity tomography (e.g. Guérin and Benderitter, 1995; Gautam et al., 2000; Kaufmann and Quinif, 2001, 2002; Sumanovac and Weisser, 2001; Roth et al., 2002; Van Schoor, 2002; Zhou et al., 2002; Gibson et al., 2004; Kaufmann and Deceuster, 2005; Deceuster et al., 2006; Abu-Shariah, 2009). Most of these methods were aimed at detecting voids or cavities filled with allochthonous sediments, sometimes in a covered karst context.

Only a few of these experiments were dealing with site-scale planning, especially in covered palaeokarst context, such as encountered in the Tournaisis area. However, accurate methodologies are needed to assess underground conditions in this specific karstic context as karst features are highly variable in three dimensions at the scale needed for building and infrastructure purposes. That is why, in this paper, the efficiency of a new strategy developed to discriminate between sound and weathered rocks based on ERI techniques is assessed.

\section{Geological and hydrogeological setting}

The Tournaisis area is located in the south-eastern part of Belgium near the French border (Fig. 1). In this region, the bedrock is mainly composed of argillaceous and siliceous Carboniferous limestone (Hennebert and Doremus, 1997) from the parautochthonous cover of the Brabant Massif (Mansy et al., 1999). This bedrock is overlain, in a non-uniform way, by a cover that mainly consists of Cretaceous marls and chalks and sandy or clayey Tertiary sediments. The thickness of this cover ranges from a few metres near Tournai to more than $100 \mathrm{~m}$ in the north-west.

In the Tournaisis area, the bedrock is marked by east to west dextral wrench faults that form part of the Melantois-Tournaisis faulted anticline structure (Fig. 1) dated as Tardi-Varsican. Later movements also affect Mesozoic and Cenozoic sediments (Hennebert, 1998).

The Palaeozoic bedrock elevations are linked with the structure even if the relief is fairly low in the area. Near the anticlinal axis, bedrock elevations range between 30 and $40 \mathrm{~m}$ above sea level. Away from the anticline axis, the bedrock plunges towards the northwest and the southwest and, consequently, the cover thickness increases. Cretaceous marls and chalks are mainly present in the western and southern parts of the Tournaisis area while Cenozoic sediments cover the whole area. The nature and thickness of the latter is mainly dependant on the actual relief, which results of their erosion.

The Carboniferous limestone aquifer of the Tournaisis area is a major water resource for Belgium and northern France. Aquifers of more limited extent are also encountered in the meso-Cenozoic sediments especially where marls or clays cover the limestone aquifer.

The structure delimits two hydrogeological domains in the Carboniferous aquifer: in the south, the Frasnes-Péruwelz-Seneffe free aquifer and, in the north, the confined aquifer of Pecq-Roubaix (Fig. 2). Since the beginning of the 20th century, intensive groundwater pumping has been carried out for deep quarry works or individual, municipal and industrial water supply. These operations resulted in differences in the way that the two hydrogeological domains developed.

In the Frasnes-Péruwelz-Seneffe aquifer, piezometric heads remained steady in most of the zone, while in the Pecq-Roubaix aquifer the piezometric heads dropped by at least $1 \mathrm{~m}$ per year between 1945 and 2000 due to a lower recharge given the presence of impermeable layers within the cover. More locally, dewatering for limestone quarries (east of Tournai) also has had a strong impact on the groundwater level. Lowering of piezometric heads has led to dewatering of the uppermost part of the limestone bedrock over broad areas.

\section{Karstic context}

Even if the fairly low relief of the Tournaisis area shows few landforms typical of karst terrains, quarry faces (Fig. 3) suggest that palaeokarst features are common in the underlying limestone. Fig. 4 shows a conceptual model of the different type of karst features found in limestone in the Tournaisis area (Kaufmann, 2000). These karst features formed prior to the deposition of the Tertiary sediments. Sinkholes occur when cover materials are washed away into the underlying bedrock voids.

\subsection{Karst features}

Karst features mostly develop in association with discontinuity planes (joints) by progressive dissolution of the carbonates leaving a soft and porous weathering residue. A typical result of this weathering process is a profile with 1 to $10 \mathrm{~m}$ wide and 10 to $30 \mathrm{~m}$ deep enlarged weathered joints (Sowers, 1996) (also called grikes or cutters elsewhere) between blocks of intact rock. The main specificity of this profile is that these enlarged weathered joints mainly contain an isalterite, as defined by Delvigne, 1998, (a weathering product with slight or no change in rock volume and remnant rock structure) except at their top. As the host limestone is siliceous, this isalterite is also siliceous but a significant content of carbonate may remain in some of the intermediate weathering products and the porosity is commonly very high (up to 50\% or more) as shown by Kaufmann et al. (1999) and Quinif 


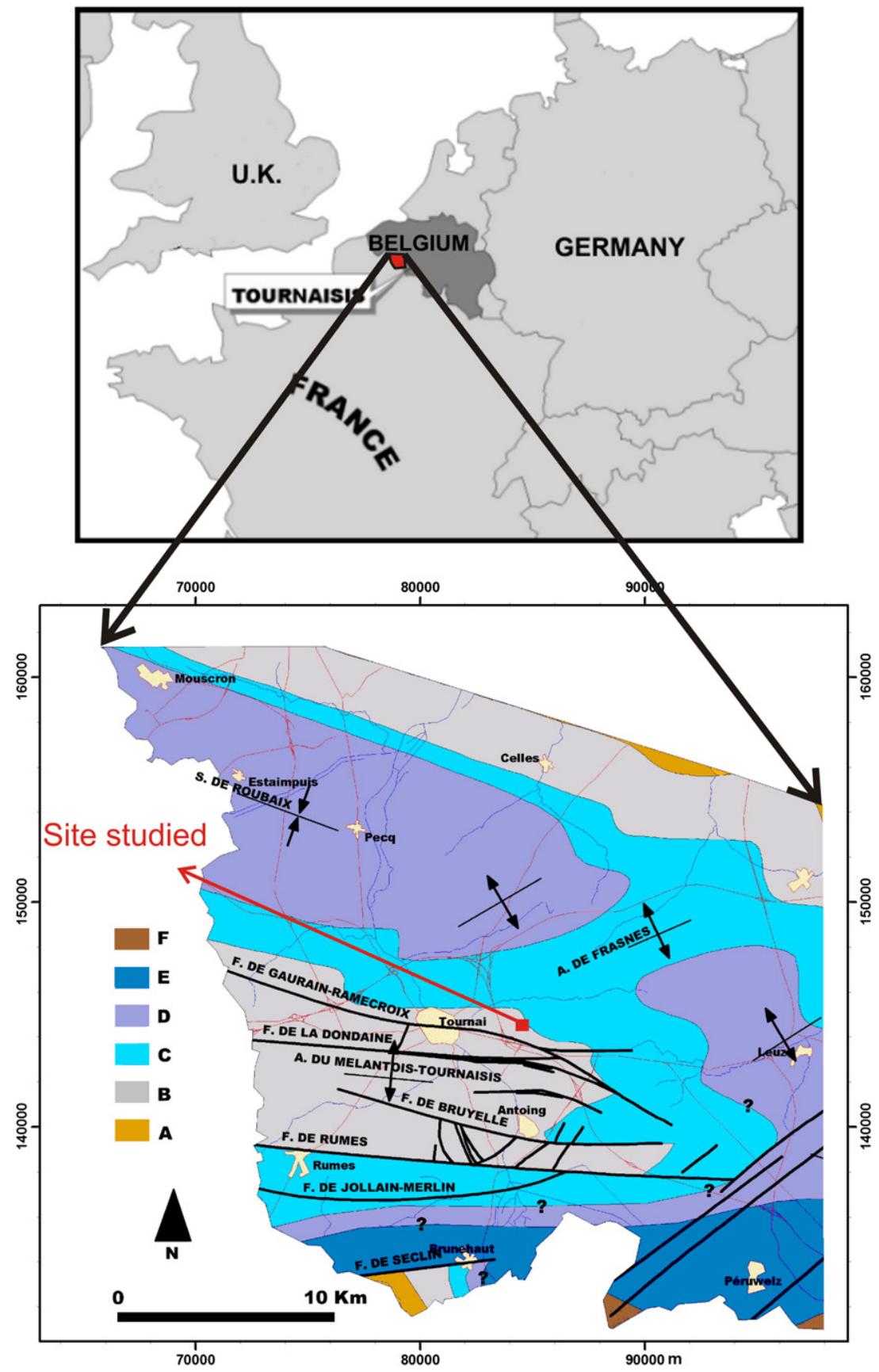

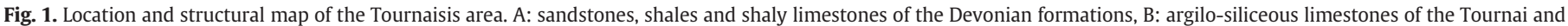

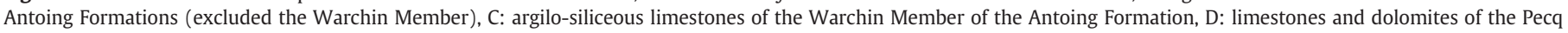
formation (Visean), E: limestones from other Visean formations, F: Namurian formations. Weathering is encountered within B, C, D and possibly E Formations.

(2010). In areas of intense weathering, palaeokarst features coalesce leading to complex geometries of weathered zones (Fig. 4). However, due to the presence of the cover deposits, no distinctive karstic landforms are visible at the ground surface, except for open sinkholes.

In the Tournaisis area, most new sinkholes develop directly above these palaeokarst features (Kaufmann, 2000), mainly in areas of water table decline in the karst aquifer as shown by Kaufmann and Quinif (1999, 2002). As a consequence of dewatering, underground voids develop by isalterite compaction, collapse and transport. This process is sped up where a perched aquifer discharges into the limestone aquifer. The cavity that is created grows and migrates upwards leading to localized subsidence or collapse of the ground surface. Processes leading to the formation of such sinkholes are depicted in Fig. 5. Though the Cretaceous cover could be viewed as a caprock, mechanically it is rather weak. Moreover, it is covered by at least several metres of poorly consolidated sediments. Thus, sinkholes in the Tournaisis area are regarded as subsidence sinkholes according to the sinkhole classification of Waltham et al. (2005). Subsidence sinkholes in the Tournaisis area are usually circular or elliptical in plan and cylindrical or conical in profile while diameter and depth commonly range between 5 and $10 \mathrm{~m}$ (Kaufmann and Quinif, 1999). Larger sinkholes up to $50 \mathrm{~m}$ in diameter and $20 \mathrm{~m}$ in depth have been reported.

\subsection{Karstic risk management}

As stated in Introduction, effective subsidence hazard management in karstic areas usually involves several levels both at the 


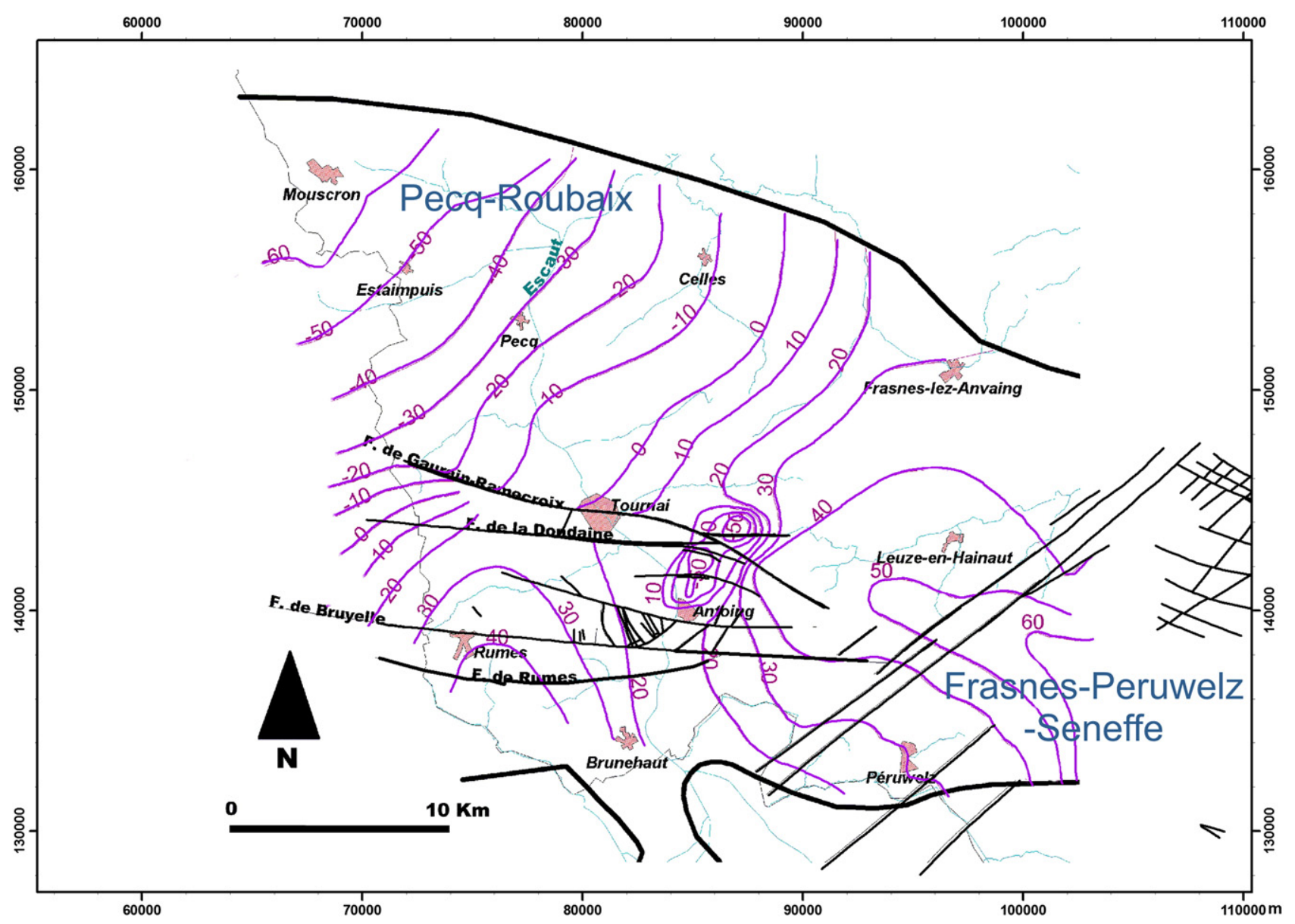

Fig. 2. Hydrogeological map of the Tournaisis area. Piezometric contour lines are given in $\mathrm{m}$ above sea level.

regional scale and at the local (or project) scale. In the Tournaisis area, karst subsidence hazard management at the regional scale is based on a three step approach. First, a danger map was prepared based on historical records (publications, newspaper cuttings, interviews, aerial photographs, old maps...) using database and GIS technology (Kaufmann and Quinif, 1999). A hazard susceptibility map was then computed from the spatial and temporal analysis of data in this inventory combined with geological and hydrogeological background knowledge. On this map, four hazard zones (negligible, low, medium and high hazard) were defined using sinkhole density and limestone rockhead position relative to the water table (Kaufmann, 2000; Kaufmann and Quinif, 2002). In the last step, a basic management map called a "karstic constraints map" was derived from the hazard susceptibility map, the land-use planning maps and the regional regulations and recommendations to control development in karstic areas.

This map shows sizeable areas of medium or high karstic constraint where the knowledge of local underground conditions has to be improved before development is allowed. Given the quasiabsence of surface evidence (except for dropout sinkholes) and the presence of cover rocks, additional knowledge about the bedrock conditions on the local scale requires geotechnical and/or geophysical investigations.

\section{Geophysical investigations}

To develop an investigation strategy adapted to the specific karstic context of the Tournaisis area at the local scale, available methods have to be evaluated from both the technical and economic points of view. Historical records indicate that first sinkhole occurrences follow rockhead dewatering by one or two decades and the planned lifetime of buildings and infrastructure projects is usually at least fifty years. Given the mechanism described above, searching for palaeokarst features (weathered rocks and enlarged weathered joints) is thus preferred to seeking buried cavities as a primary target.

From a technical point of view, cross-hole techniques are probably the best choice in terms of resolution. However a significant number of boreholes is required to reconstruct the 3D geometry of palaeokarst in the investigated area. Therefore, cross-hole techniques are mainly considered only for large projects of limited extent that cannot be easily relocated and would not be affordable for most of the other projects. Thus, for the latter, surface geophysical methods are a suitable alternative.

Since palaeokarst features are covered by at least several metres of more conductive materials (clays, argillaceous silts or marls), some geophysical methods are unsuitable for their detection. The penetration depth of electromagnetic methods or ground penetration radar techniques in such ground is very limited. Even if seismic surveys and especially surface wave methods seem promising for the detection of shallow cavities (e.g. Grandjean and Leparoux, 2004; Gelis et al., 2005; Xia et al., 2007), further research on the application of these methods to karstic features encountered in the Tournaisis area is still needed.

As field observations and laboratory measures on samples show that isalterite within enlarged weathered joints has a high to very high porosity and a high saturation ratio, the weathered joints are expected to be much more conductive than limestone. Given those facts, a contrast in density will also exist between isalterite and limestone. However, as this contrast is smaller than in the case of water or air-filled cavities, gravity anomalies are expected to be small even if 
1
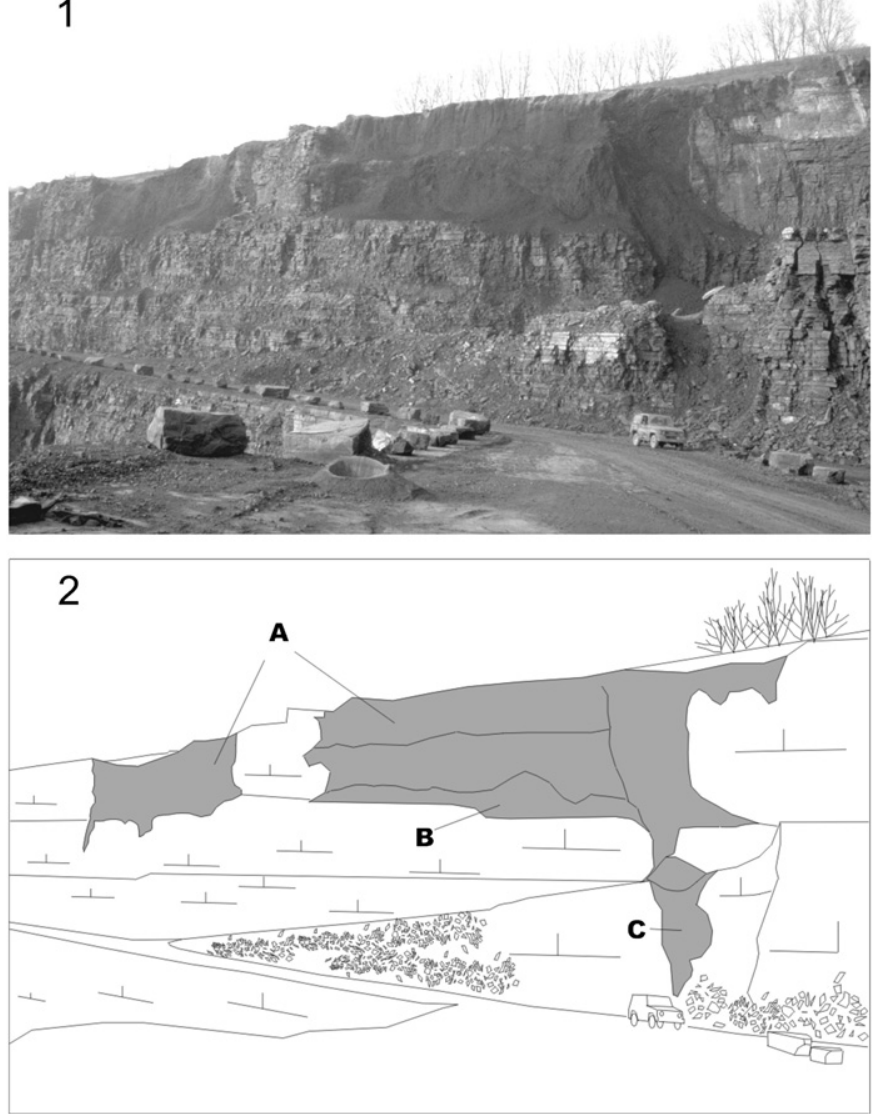

Fig. 3. Photograph (1) and interpretative sketch (2) of a quarry face located near the "Rieu de Warchin" site showing typical weathered zones found in the Tournaisis area. Symbols A, B and C are defined on Fig. 4.

weathered zones are usually larger than isolated cavities. Consequently, investigations have focussed on the use of electrical resistivity imaging (ERI) applied to the specific context of covered palaeokarstic features such as those encountered in the Tournaisis area. A well documented site strongly affected by dropout sinkholes was selected as a case study (Fig. 1). This site is located at GaurainRamecroix, $10 \mathrm{~km}$ east of the city of Tournai, near a stream called "Rieu de Warchin". ERI maps are compared with results from geotechnical investigations (CPTs and boreholes). A site-scaled decision-support scheme is then proposed based on comparison between CPTs data and the interpreted resistivity model. Performance tests using borehole data have been conducted to validate the proposed decision-support scheme and compare it with conventional geotechnical investigations. This decision-support scheme may be used to design suitable building foundations.

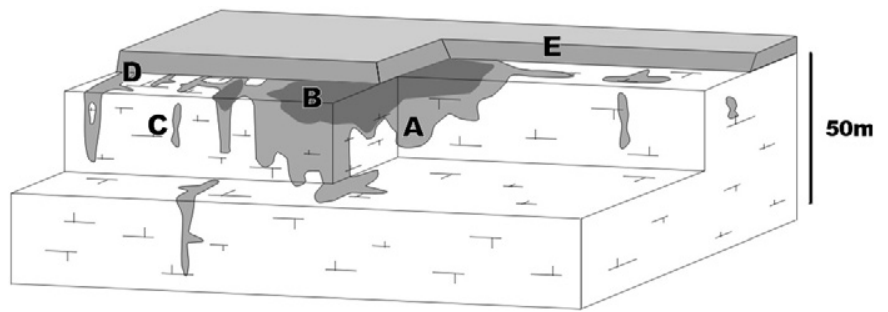

Fig. 4. Synthesis of typical palaeokarstic features visible in the Tournaisis area; A: a wide zone of weathering products; B: "cherts breccias" containing consolidated alterite at the top of wide weathered zones; C: narrow weathered joints; D: enlarged weathered joints also known as "weathered corridors"; E: cover materials (after Kaufmann, 2000)

\section{Case study: "Rieu de Warchin" site}

\subsection{Site description}

This site is located about $500 \mathrm{~m}$ west of a limestone quarry. Water abstraction for quarry works locally increases the regional decline in the level of the water table. Since 1984 many sinkholes (Fig. 6) opened up along the stream bed (Quinif et al., 1985; Quinif and Rorive, 1990; Van Rantergem et al., 1993; Kaufmann and Quinif, 1999; Kaufmann, 2000). Several stream losses were recorded over a period of about 10 years in spite of the efforts to make the stream bed watertight and prevent massive surface water infiltration. In 1989 a sinkhole occurred below the foundations of a house leading to its complete destruction. In 1992, another sinkhole occurred below a settling basin of a nearby limestone quarry. The raw sewage percolated through karst features and finally discharged inside the quarry located a few hundred metres east.

Excavation works were undertaken over and around sinkholes to develop an accurate geological model (Fig. 7). Depth to bedrock on this site is about 3 to $4 \mathrm{~m}$ and the cover mainly consists of silts and clayey sands. Excavation showed that sinkholes occurred where the bedrock was highly weathered within joints 1 to $2 \mathrm{~m}$ wide oriented $\mathrm{N} 105^{\circ} \mathrm{E}$ and $\mathrm{N} 20^{\circ} \mathrm{E}$ (Fig. 7B). These directions of joints are consistent with the regional structure shown in Fig. 1.

\subsection{Acquisition design}

A 2.5 m electrode spacing was selected to reach a maximum depth of investigation of about $12 \mathrm{~m}$ with enough resolution to image the enlarged joints. A combination of dipole-dipole (DD) and WennerSchlumberger (WS) arrays was used as Kaufmann and Quinif (2001) and Zhou et al. (2002) showed that this combination of arrays gives the best results in the type of karstfound in this area. The imaging resolution of DD arrays is usually one of the best for the location of vertical structures but this array is more subject to noise contamination especially for large $n$ numbers ( $n$ is the number of times the distance between pairs of voltage and current injection electrodes is greater than the separation between electrodes used to inject current). WS arrays are good at depth determination with a good imaging resolution and are less sensitive to noise. Imaging with mixed arrays produces models similar to the better resolved image among the individual array used as reported by Dahlin and Zhou, 2004. To check the ability of the survey design to detect expected palaeokarstic features, this acquisition protocol was tested on a synthetic 2D model (Fig. 8A). A single $2.5 \mathrm{~m}$ wide weathered joint is located at the centre of the model and is orthogonal to the acquisition profile. At this position a $1.1 \mathrm{~m}$ high step in the rockhead is also present (a typical configuration seen in quarries) to test the vertical resolution. Resistivity values of each material were chosen from typical values found in the Tournaisis area (topsoil: $100 \mathrm{ohm} . \mathrm{m}$, silts: $30 \mathrm{ohm} . \mathrm{m}$, wet alterite: 15 ohm.m, limestones: 600 ohm.m).

The model response was computed with Res2DMod software and the inversion was carried out within the Res2DInv software, both developed by Geoelectrical Imaging. A least-squares inversion scheme was selected and no preferential flatness filter was applied.

Fig. $8 \mathrm{~B}$ and $\mathrm{C}$ shows the reconstructed models simulated with DD ( $a=1$ spacing with $n$ varying from 1 to 7 and $n=1$ with a varying from 1 to 7 spacings), respectively without and with a $10 \%$ Gaussian noise added. Fig. 8D and E presents the reconstructed models simulated with WS ( $a=1$ spacing with $n$ varying from 1 to 7 and $n=1$ with a varying from 1 to 7 spacings), respectively without and with a $10 \%$ Gaussian noise added. Fig. $8 \mathrm{~F}$ and $\mathrm{G}$ presents the reconstructed models simulated with both DD and WS arrays respectively without and with a $10 \%$ Gaussian noise added. These simulations show that the weathered joint has been observed in reconstructions based on DD and mixed arrays. As expected, the weathered joint is clearly 
1

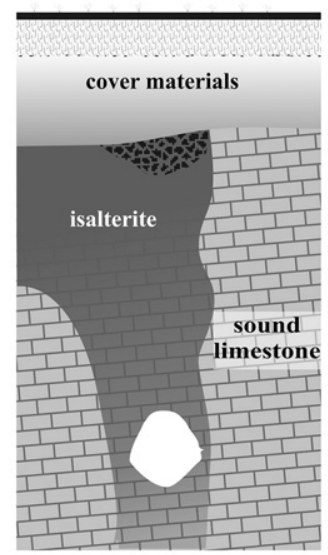

A

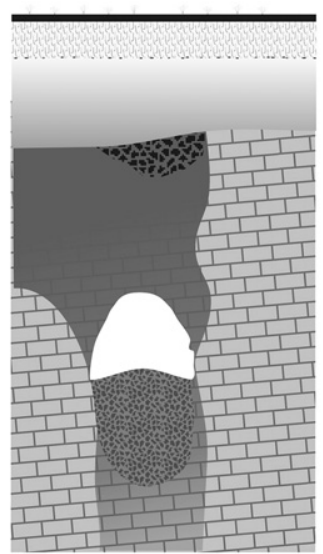

B

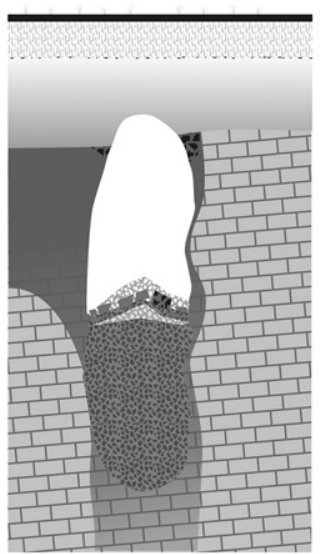

C

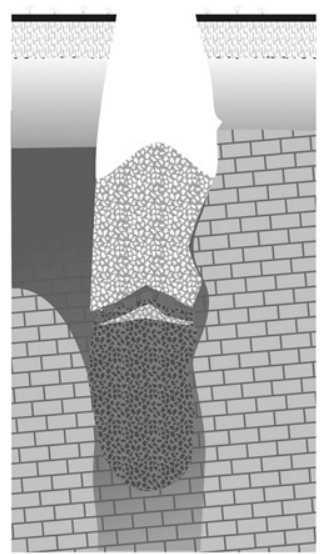

D

2

cover materials

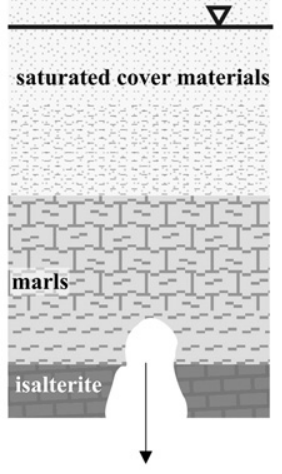

A

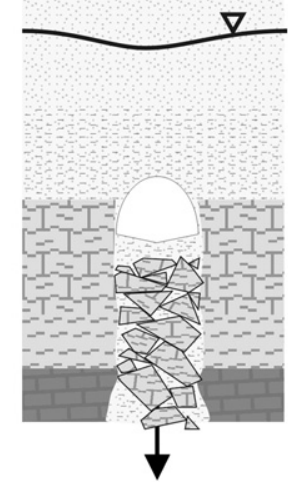

B

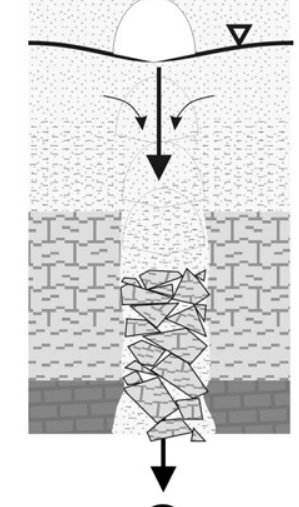

C

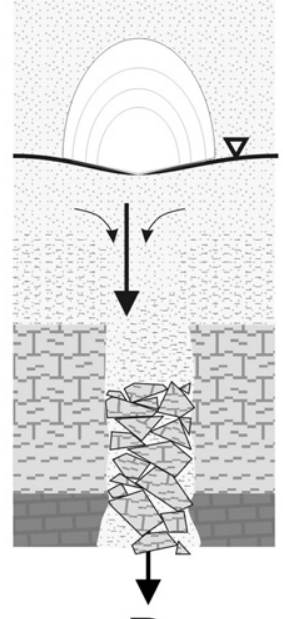

D

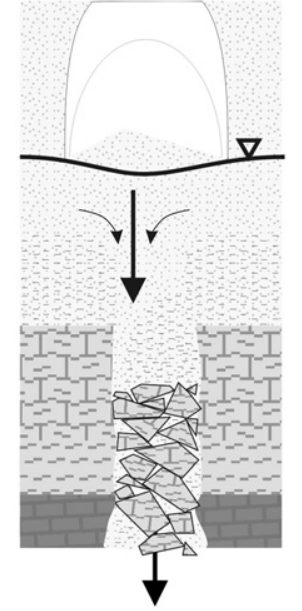

$\mathbf{E}$

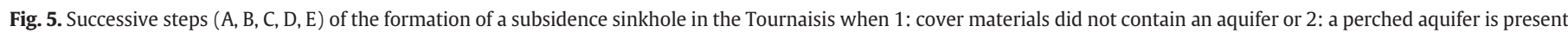
inside cover materials (after Kaufmann, 2000).

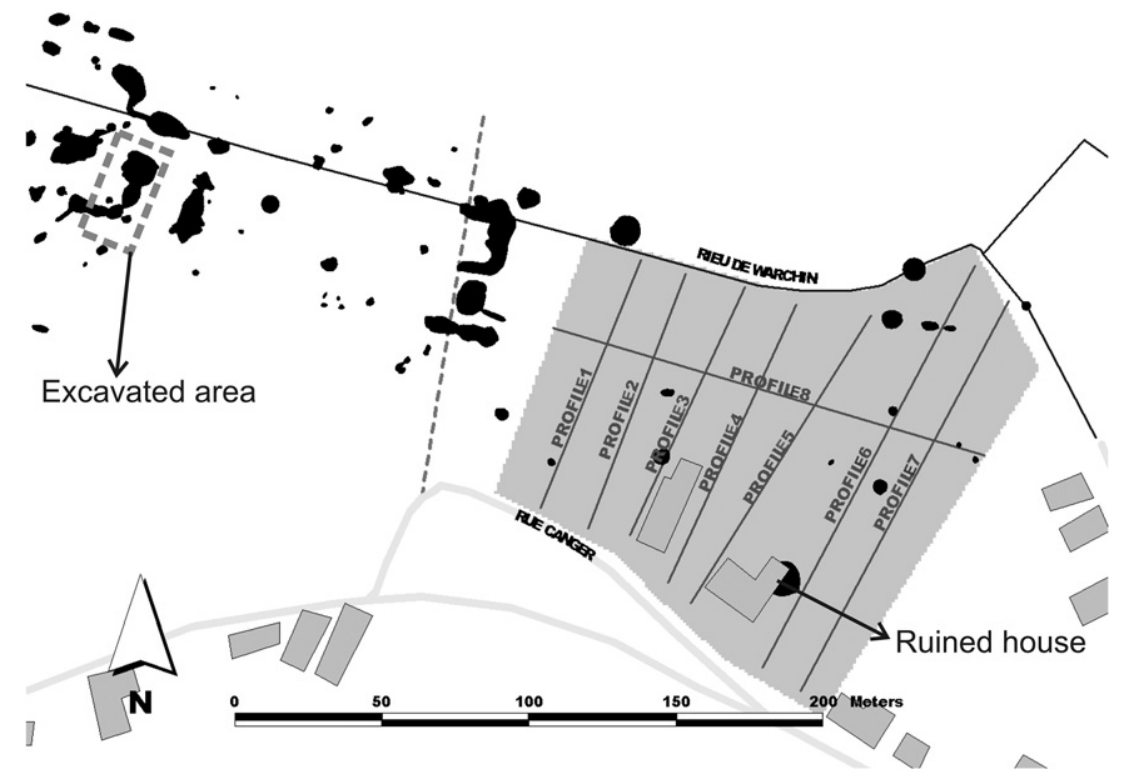

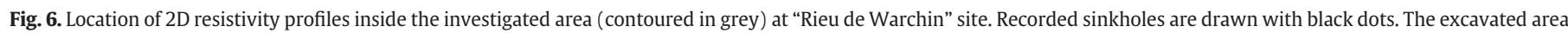
is highlighted with grey dashes. 

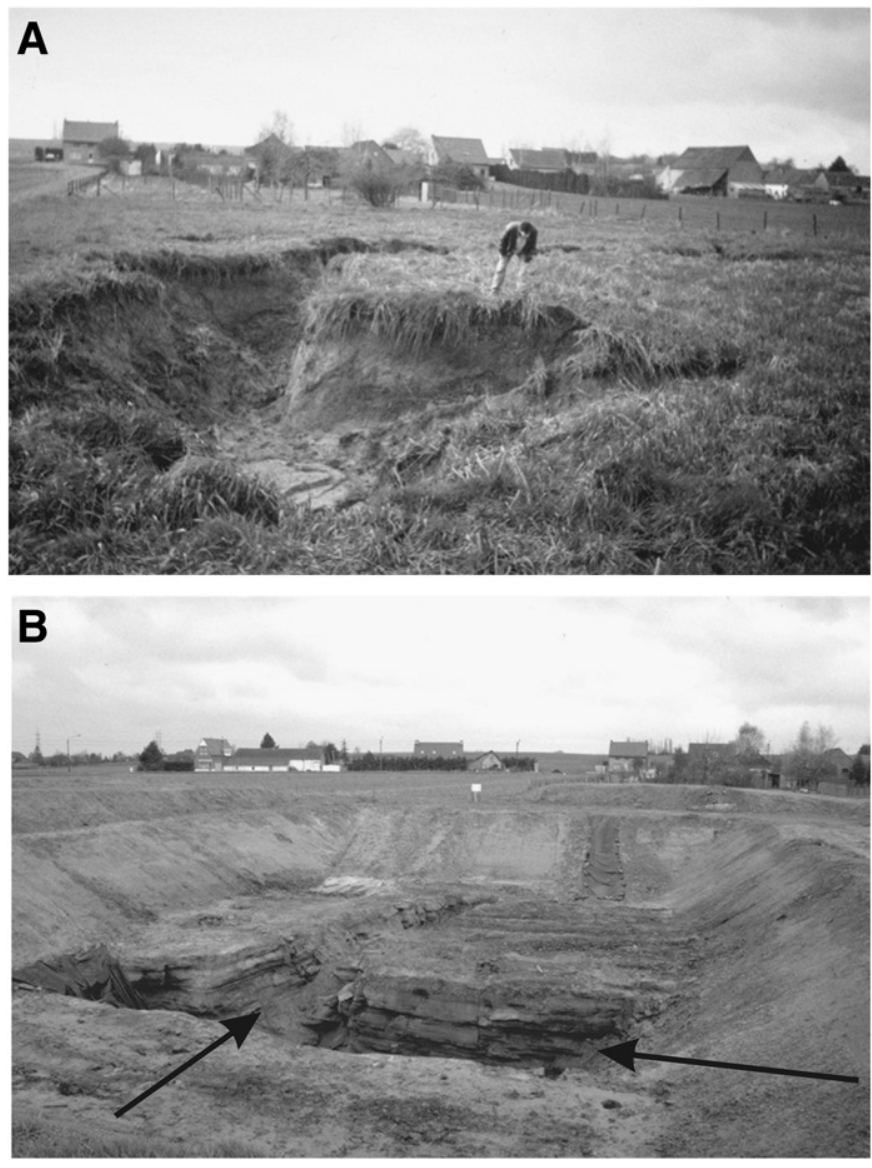

Fig. 7. Photographs of the excavated area (A) before excavation and (B) after excavation. Slots are located with arrows.

identified in the DD images even when noise is added. On the models reconstructed from WS, a faint resistivity anomaly is located over the modelled slot and the resistivity gradients around the top of the bedrock are significantly weaker. On the mixed arrays models (Fig. 8F and $G$ ), the weathered joint is also well located and its resistivity is fairly well defined. Furthermore, incorporating WS in addition to DD in the inversion leads to reconstruction of a section with a good resolution and with fewer artefacts than DD alone, even for the noisy dataset. Moreover, in real acquisitions, incorporating WS allows imaging of parts of the section where DD measures may be rejected due to noise.

\subsection{Field experiment}

Geophysical surveys were conducted on this site between the "Rieu de Warchin" stream and the Rue Canger (Fig. 6). They consisted of $2 \mathrm{D}$ resistivity measurements along 8 profiles each about 100 to $150 \mathrm{~m}$ long. Seven quasi-parallel profiles are oriented more or less $\mathrm{N} 25^{\circ} \mathrm{E}$. Spacing between these profiles was about $15 \mathrm{~m}$ so that conductive weathered joints of the expected size would be sensed even if located between profiles. The last profile was oriented $\mathrm{N} 105^{\circ} \mathrm{E}$ and crossed all the others approximately at right angles.

The first processing consisted of the inversion of each individual profile dataset using Res2DInv. A finite-element method to solve the forward problem and a smoothness constrained least-square method (Loke and Barker, 1996a) were used.

Forty-six static cone penetration tests and fifteen boreholes were also undertaken to cross-check the interpretations (Kaufmann, 2000; Kaufmann and Quinif, 2001). Continuous flight hollow-stem augering in soils and soft weathered limestone (alterite) was used while limestone was drilled with a down-the-hole hammer penetrating at least $1 \mathrm{~m}$ into sound rock to discriminate small 'floating' blocks from larger blocks or pinnacles. In this way, both disturbed and undisturbed samples were collected in soft soils and the position of the soil/rock interface was estimated.

Fig. 9 shows the 2D resistivity tomograph computed along profile number 8 (oriented E-W) as well as the results of the geotechnical investigations. From data from boreholes T06 and T10 three ranges of resistivity are associated with different lithologies:

- <50 ohm.m: corresponding to silts and clayey sands at the surface and to highly weathered limestone at depth;

- resistivities between 50 and $250 \mathrm{ohm}$.m: corresponding to dryer residual soils, less weathered limestones;

- >250 ohm.m: corresponding to competent bedrock. These resistivities are still low but are typical of the argillaceous limestones of the Gaurain-Ramecroix Formation.

Fig. 9 shows a continuous 3 to $4 \mathrm{~m}$ thick layer of low resistivities $(<50$ ohm.m) at the surface. These low resistivities correspond to cover materials made up of silts and clayey sands. Below this layer the tomograph shows intermediate to high resistivities at depth. The top of the bedrock seems to be horizontal as confirmed by geotechnical tests. However, changes in resistivity are clearly visible within the bedrock. Indeed, intermediate resistivities are found at bedrock depth in the first $60 \mathrm{~m}$ of the tomograph. This probably indicates that the bedrock is more fractured or weathered in this part. A broad vertical resistivity anomaly is detected at about $100 \mathrm{~m}$ along the $X$-axis. Boreholes (T05, T06 and T18) showed that this zone corresponds to highly weathered limestone.

Inverted resistivity sections along the other profiles oriented from south to north are given in Fig. 10. Some trends are common between several adjacent profiles, which indicate a lateral continuity of the anomalies. To improve the visualization of underground conditions, a 3D model was interpolated from the results of the separate 2D inversions. Resistivities of each $2 \mathrm{D}$ model block were affected to the center of the blocks. This step was conducted with MATLAB using a linear interpolation based on a 3D Delaunay triangulation on a $1 \mathrm{~m} \times 1 \mathrm{~m} \times 0.5 \mathrm{~m}$ regular grid. Paraview 3.10.0 was then used to visualize and analyze this model.

\subsection{Interpreted resistivity model}

As ranges of resistivities associated with the different geological formations overlap, it is difficult to discriminate the formation encountered based on resistivity thresholds. Moreover, the variability of the weathering intensity, as well as the spatial distribution within the weathered formation may be dependent on depth as suggested by the observations of weathered zones in the Tournaisis area (as described before in the karstic context section).

To discriminate sound from weathered rock, the 3D resistivity model was compared with the results of CPT tests. The histogram of CPT refusal depths (Fig. 11) shows two subsets: in the first one CPT refused at depths between $3.6 \mathrm{~m}$ and $5 \mathrm{~m}$ corresponding to silts directly covering sound limestone; in the second one, refusal depths varied from 5.8 to $11.8 \mathrm{~m}$ and indicated the presence of alterite below silts. For these two subsets, vertical resistivity profiles were extracted from the 3D model at CPT locations. The distributions of the resistivity profiles from the two CPT subsets were then compared using a box-plot representation for each $1 \mathrm{~m}$ slice (Fig. 12). The resistivity range and inter-quartile width of the first subset are larger than for the second subset. Median resistivities of all slices are clearly higher for the first subset. The overlapping of resistivity ranges include only about one quarter of the data. Based on this analysis, an empirical relationship between resistivity and depth was established to distinguish between the two possibilities (sound limestone directly beneath silts or alterite beneath silts). This relationship was obtained 
$30 \quad 60010915$ Ohm.m

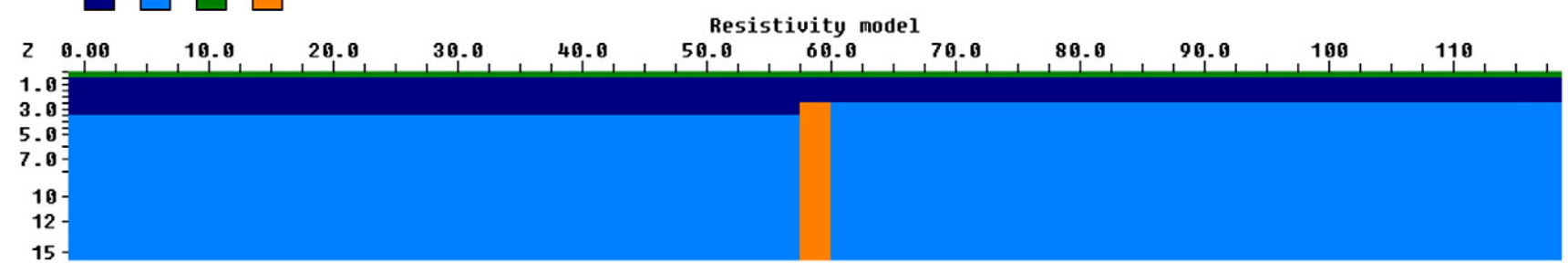

\section{A. Initial model}

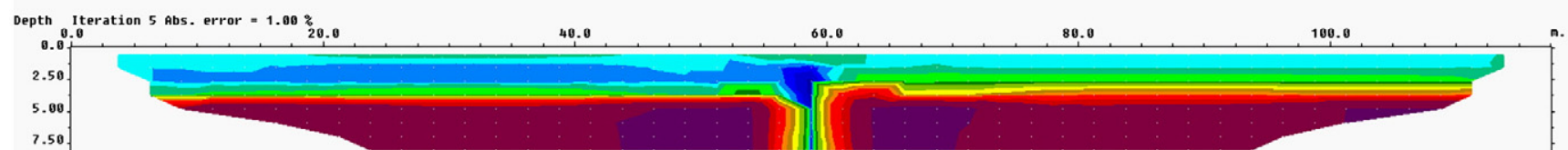

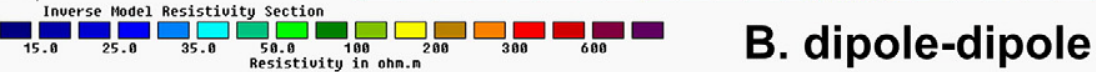

Unit electrode spacing $2.50 \mathrm{n}$

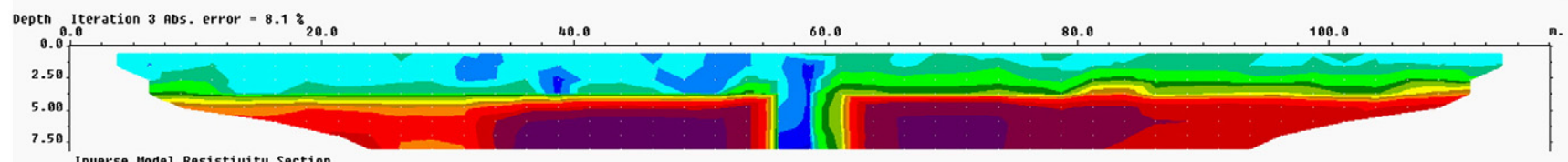

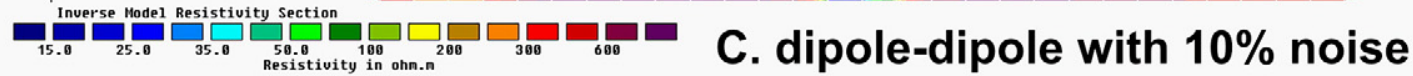
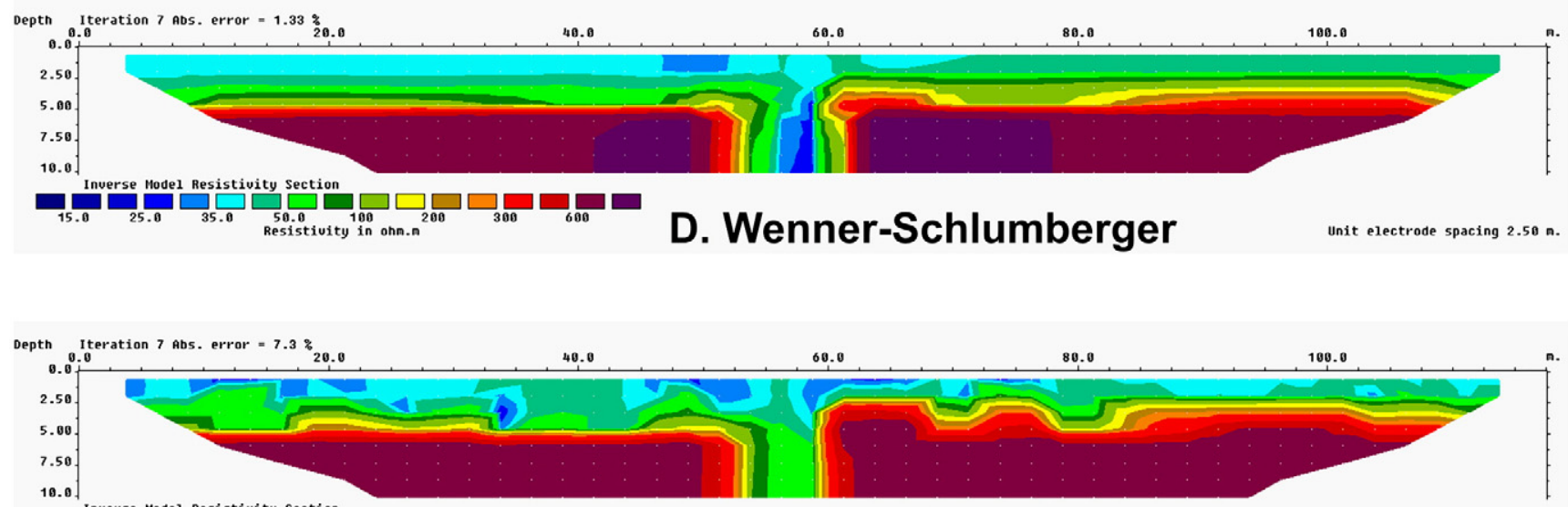

$\square_{15.0}^{\text {Inverse Model Resistivity Section }}{ }_{25.0} \square_{35.0} \square_{20.0} \square_{300} \square_{600} \square$

E. Wenner-Schlumberger with $10 \%$ noise
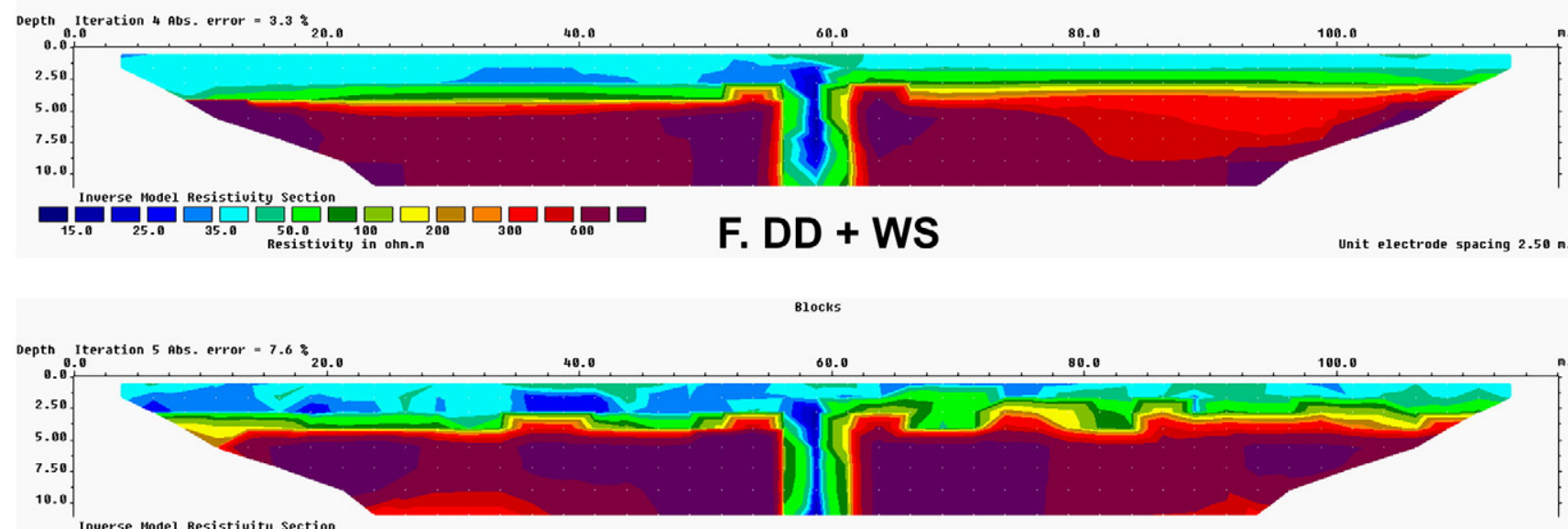

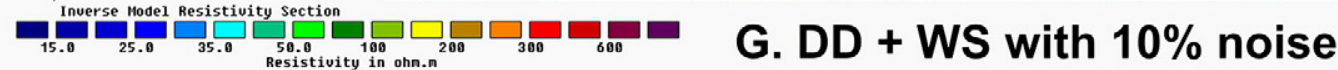




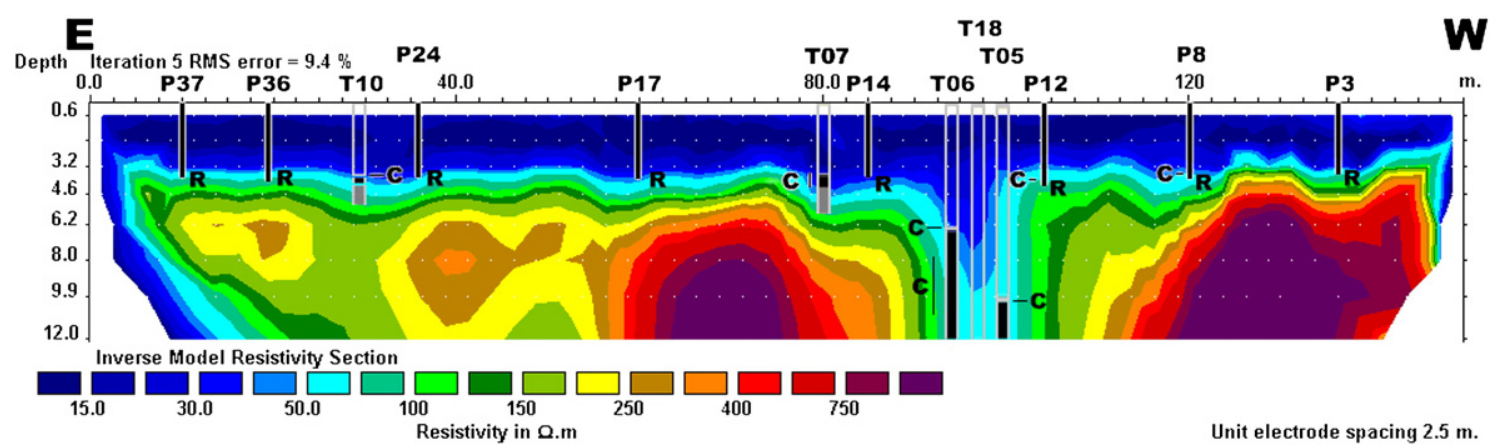

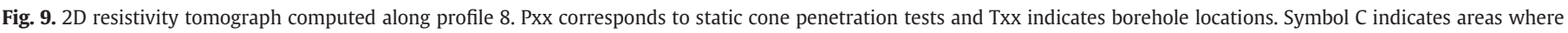
shocks were recorded during CPT. Symbol R indicates that CPT refused.

from a linear regression of the mean of the first quartile of the first subset and the third quartile of the second subset with depth $\left(R^{2}=0.99\right)$. Using this relationship to discriminate between zones interpreted from CPTs as weathered and sound limestone explains about $75 \%$ of the dataset. To visualize the rockhead, the difference between the 3D resistivity model and values from this relationship for each block from 3.5 to $12 \mathrm{~m}$ depth was computed. The volume including positive values of this difference and limited by the zero value isosurface was interpreted as sound limestone. The upper layer was considered to be cover materials, as indicated by CPT interpretations. It may be difficult to discriminate between these materials and weathering products. However, as cover materials present below $3.5 \mathrm{~m}$ deep are located over alterites present in palaeokarstic features, regrouping them does not affect the general interpretation.

Fig. 13A presents a 3D view of the interpreted resistivity model. Cover materials are depicted in yellow, sound limestone in shade of blues and weathering products in grey. Fig. 13B and C shows similar views of the interpreted resistivity model respectively without cover materials and with sound limestone only. In the southern part of the investigated area, a wide zone of weathering products is clearly visible (1). This zone is oriented approximately $\mathrm{N} 110^{\circ} \mathrm{E}$, which is consistent with one of the main directions of weathered fractures and enlarged weathered joints in the studied area. This weathered zone extends below the destroyed house where a sinkhole occurred in 1989 (Fig. 6). A weathered zone showing a sinkhole profile (approximately $17 \mathrm{~m}$ in diameter) was also detected in the northern part (2) of the area, where no sinkhole had been recorded. Narrower weathered joints (3) are also visible in Fig. 13D. They are also oriented approximately $\mathrm{N} 110^{\circ} \mathrm{E}$. Another weathered zone (4) located along the left edge of the model which is consistent with the alignment of sinkholes near the "Rieu de Warchin" stream.

\subsection{Comparison between geotechnical and geophysical results}

Fig. 14A shows a map of the depth of refusal of cone penetration tests based on a natural neighbour's interpolation (on a $0.25 \mathrm{~m} \times 0.25 \mathrm{~m}$ grid). In Fig. 14B, ERI interpreted depths to bedrock are drawn, also using a natural neighbour's interpolation (on a $0.25 \mathrm{~m} \times 0.25 \mathrm{~m}$ grid). Fig. $14 \mathrm{C}$ shows the difference map (A-B) between interpolated depths to bedrock derived from CPT's and ERI.

In general, absolute differences in reconstructed depths are in the order of $1 \mathrm{~m}$ (in grey in Fig. 14C) which does not represent a significant difference for most engineering problems. Indeed, large anomaly zones are reasonably well reconstructed with cone penetration tests on this site. However, near the boundaries of the difference map, discrepancies due to the scarce spatial coverage of CPT's can be seen (in blue to the north and the south). Zone 1 detected on ERI (see Fig. 13) under the garden surrounding the houses is not well defined in Fig. 14A. This is also linked to a lack of CPT data due to accessibility constraints.

The sinkhole shape anomaly (2) was densely sampled along a single line with nine CPTs. Despite that, the complex shape of the anomaly seems to be better reconstructed in Fig. 14B especially in the direction perpendicular to the CPT's alignment. This discrepancy in depth differences in the surrounding area is probably due to an interpolation artefact. The same type of small artefacts is also visible on anomalies (3a) and (6). The discrepancy in depths at point (5) shows that small karst features may be missed using point data, even if, as in this study, the number of CPTs was quite large. However, these small karst features may still threaten the stability of buildings above.

In conclusion, the two depth to bedrock maps show an overall consistency. Qualitatively, the ERI imaging computed from the depths to bedrock model deduced by the application of an empirical relationship on the interpreted resistivity model seems to be able to reconstruct the complex geometry of karst features on this site quite well. This suggests that the combination of ERI imaging with a few CPTs enables discrimination between karst features and bedrock in a better way than by using resistivity threshold values only.

\section{Site-scale design based on interpreted resistivity model or CPT depth to bedrock model?-performance tests}

\subsection{Methodology}

To assess quantitatively the efficiency of the proposed decisionsupport scheme, performance tests were conducted considering two typical engineering problems that could be encountered when dealing with site-scale planning in covered karst areas, such as in the Tournaisis area. The first engineering problem studied (case 1) is for deep foundations of buildings (e.g. pile foundations). The second engineering problem examined (case 2) is the horizontal sinking of pipes (e.g. sewer pipes, high-pressure pipelines, gas pipes, etc.). These two engineering problems were tested using two hypotheses: (Hyp. A) sound bedrock is present at a depth less than $10 \mathrm{~m}$; (Hyp. B) bedrock is weathered at least in the first $2 \mathrm{~m}$ below $3.5 \mathrm{~m}$ depth.

Performance tests were conducted using statistical criteria in a contingency table (Table 1) as developed by Pearson, 1904. A contingency table is a type of table in a matrix format that displays the (multivariate) frequency distribution of the variables. The logs of 

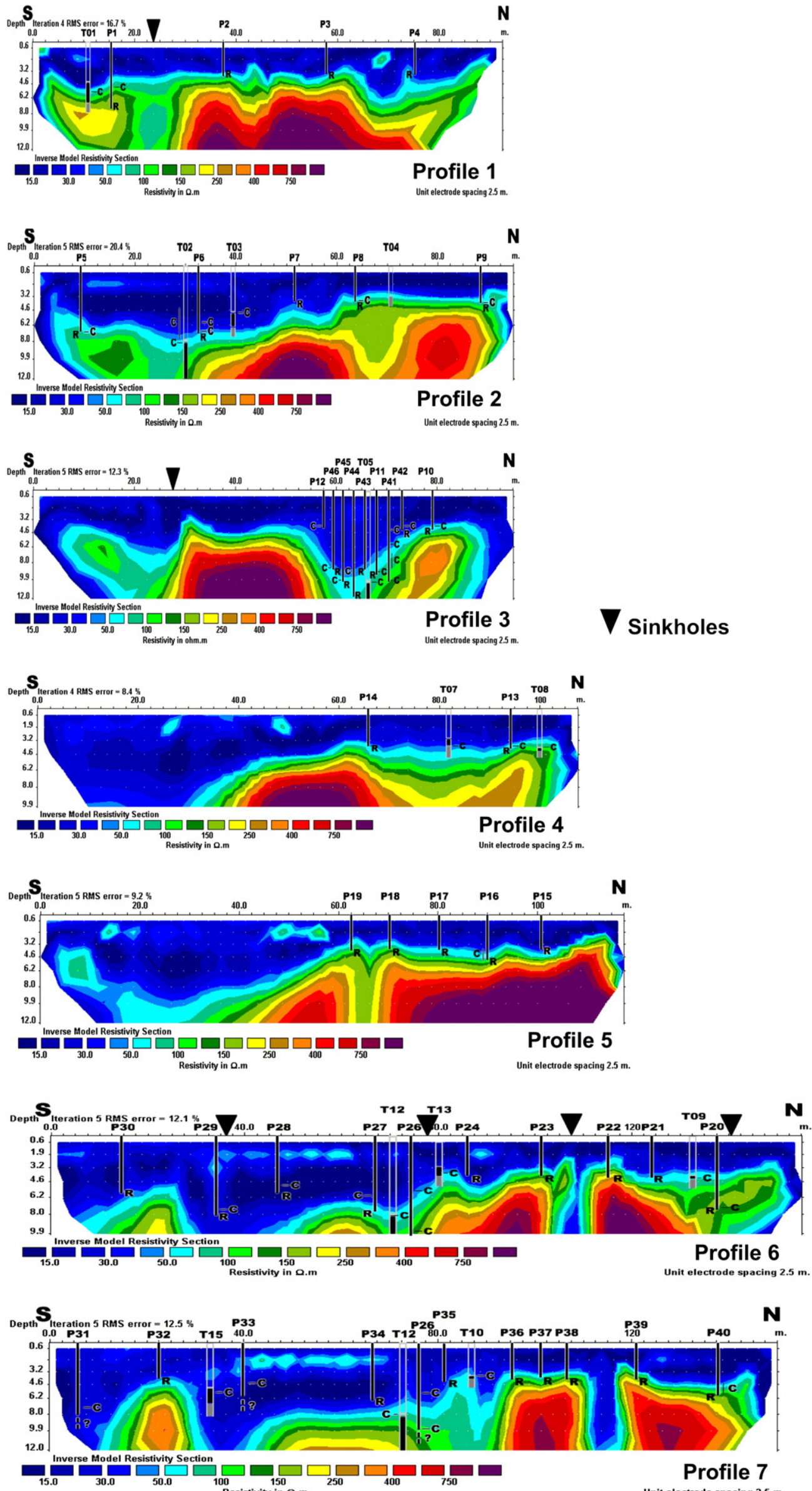


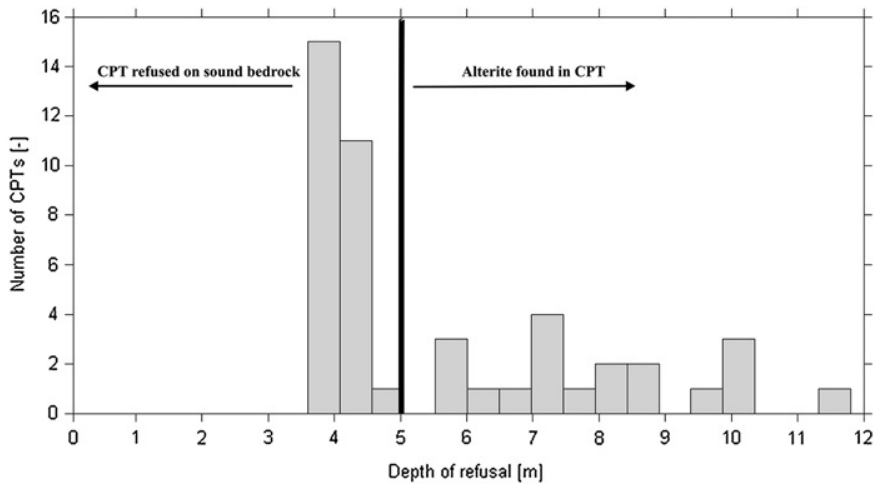

Fig. 11. Histogram of CPT depths of refusal including interpretations on bedrock weathering.

the sixteen boreholes drilled on the site were used as 'ground truth' for each case studied. Predicted conditions were computed at each borehole location using three statistical parameters computed on resistivities located in the vicinity of the boreholes: median, mean + one standard deviation (mean + std), maximum. They were defined as true if the statistical parameter studied was higher than the resistivity from the empirical resistivity relationship at a depth lower than the hypothesis tested. The statistical parameters were computed on six different support grids to estimate the influence of the support on the decision process.

Statistical performance of the tests was assessed through accuracy, $F$-measure $\left(F_{\beta}\right)$ and Matthews Correlation Coefficient (MCC). The accuracy is defined as the proportion of true results (true positive (TP) and true negatives (TN)) in the population. F-measure is also a measure of test's accuracy considering both the precision (proportion of the true positives against all the positive results (TP + FP)) and recall (proportion of the true positives against the positive results that should have been returned $(\mathrm{TP}+\mathrm{FN}))$ and is given by:

$F_{\beta}=\left(1+\beta^{2}\right) \times T P /\left(\left(1+\beta^{2}\right) \times T P+\beta^{2} \times F N+F P\right)$

where $\beta$ indicates the number of times as much importance was attached to recall as precision (van Rijsbergen, 1979). For this study, $\beta=0.5$ for case 1 , meaning that false positive results have to be minimized (areas with depth to bedrock deeper than suitable for the selected foundation technique have to be detected as in these areas foundations will not be efficient or economically suitable) and $\beta=2$ for case 2 , meaning that false negative results have to be minimized (areas where sound rocks are present at the depth range studied have to be detected as in these areas the sinking of pipes would not be possible using the same device as in weathered areas, thus leading to unexpected cost overrun).

The MCC (Matthews, 1975) is a correlation coefficient between the observed and predicted binary classifications and is related to the chi-square statistic for a $2 \times 2$ contingency table:

$|\mathrm{MCC}|=\sqrt{\frac{\chi^{2}}{n}}$

where $n$ is the total number of observations (here $n=16$ ). The MCC can be calculated directly from the contingency table using the

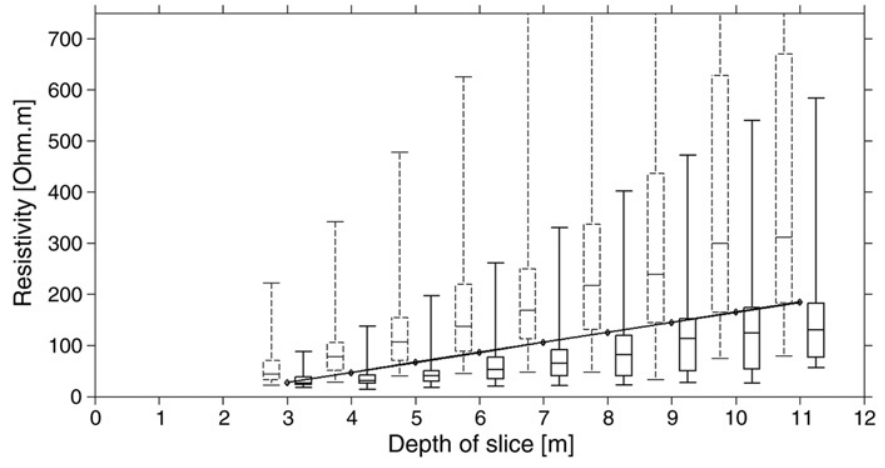

Fig. 12. Box-plots of resistivities of the reconstructed model at CPTs locations. Boxplots for locations where CPTs showed the presence of alterites are drawn with thick lines, others with dashed lines. The empirical relation discriminating these two sets is plotted with diamonds.

formula:

$|M C C|=\frac{T P \times T N-F P \times F N}{\sqrt{(T P+F P) \times(T P+F N) \times(T N+F P) \times(T N+F N)}}$

The MCC value ranges between -1 and +1 . A coefficient of +1 represents a perfect prediction, 0 an average random prediction and -1 an inverse prediction. As related to the chi-square statistic, the MCC was used to determine if the observed deviation from the null hypothesis was significant (Table 2).

To compare the reliability of the two methods of investigation, performance tests were also conducted on the depth to bedrock model computed from CPT data. However, in this case, only five support grids were tested as the standard acceptable error for the location of the bedrock (z-direction) is similar for the two available datasets (CPTs and boreholes) and fixed to $500 \mathrm{~mm}$. Predicted conditions were mapped as true if the computed depth to bedrock of Fig. 14A was above the limit considered in the hypothesis. Contingency tables were then computed for each decision support grid.

Finally, the results of the performance tests were compared and discussed to evaluate the potential and limits of both methods of investigation in predicting geological conditions and thus helping decision makers dealing with such engineering problems.

\subsection{Results of performance tests: Hyp. A}

Table 3 shows the results of the performance tests conducted on the resistivity depth to bedrock model for Hyp. A. In general, MCC values show that the tests were at least significant indicating that the proposed decision scheme is able to detect the presence of sound rock at $10 \mathrm{~m}$ depth with a probability greater than $95 \%$ whatever the combination of supports and statistical parameters used. In detail, performance tests using the median resistivity of the blocks included in the support grid considered present smaller MCC values than those conducted with the mean + std and maximum parameters. The accuracy ranges between $75 \%$ and $81 \%$ meaning that at least $75 \%$ of the predicted conditions are well classified. For the engineering problem considered in case 1 , the median resistivity seems a good estimator to locate areas where the depth to bedrock allows piling of foundations $\left(F_{0.5}>85 \%\right)$. However, for case $2, F_{\beta}$ is of the order of $60 \%$ which may not give sufficient confidence in the location of areas where sound rock is not present above $10 \mathrm{~m}$ depth.

Performance tests conducted using the mean + std parameter are highly significant and the accuracy is greater (88\%) than for the median 

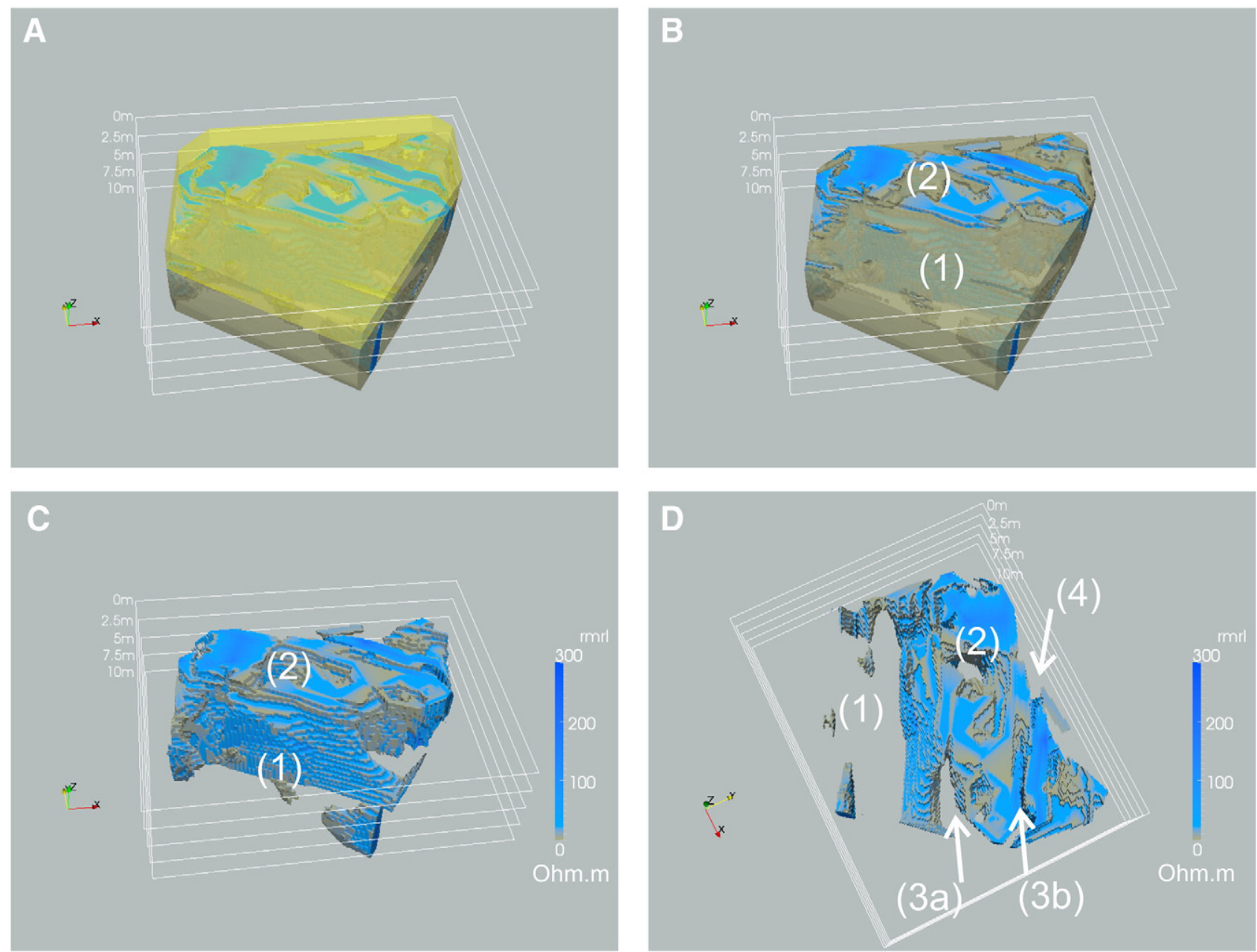

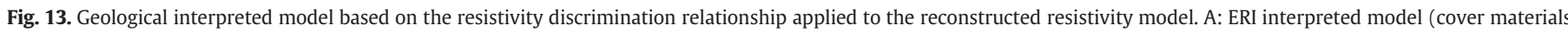

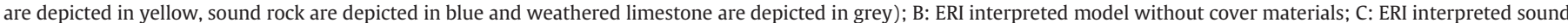

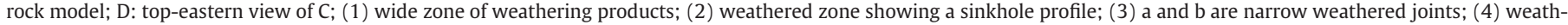
ered zone located along the northern border of the site.

parameter. The results of these tests are independent of the chosen support grid. The $F_{\beta}$ accuracy of the decision scheme based on ERI data is about $80 \%$ for case 2 and about $95 \%$ for case 1 which provides sufficient confidence in the results to design properly the planned engineering actions. Similar results were found for the maximum criterion for the four smaller support grids. Using larger support grids leads to minimizing the number of false negatives but also to increasing the number of false positives by incorporating blocks with higher resistivities in the support considered. However, using the maximum criterion and a $5 \mathrm{~m} \times 5 \mathrm{~m} \times 1 \mathrm{~m}$ support grid results in a very highly significant test for Hyp. A.

Table 4 shows the results of performance tests conducted on the CPT depth to bedrock model. These tests were not significant for both supports. For three of them, MCC values cannot be calculated as predicted conditions were always true. Test's accuracies ranged between $56 \%$ and $69 \%$ as predictive values are quasi-always true and the proportion of true ground proofs is $56 \%$ of the dataset. $F_{\beta}$ values have no sense in practice as the tests are not significant. Therefore, testing Hyp. A based on CPT data is unreliable and similar to a coin toss even if, in this study, boreholes are located near CPT locations. This can partly be explained by the presence of small blocks or consolidated alterite at the top of weathered palaeokarst features, which sometimes limits the depth of penetration of CPT.

\subsection{Results of performance tests: Hyp. B}

The results of the performance tests conducted on Hyp. B are summarized in Table 5. The tests were significant ( $\mathrm{MCC}=0.49$ ), except from the test using the maximum criterion in combination with the largest support grid. Test accuracies are of the order of 75\%, except from the three tests highlighted in Table 5, which show larger values. In most of the tests, $F_{\beta}$ accuracies are about $71 \%$ for case 1 and $38 \%$ for case 2. These accuracies are much smaller than those found for Hyp. A. However, using the mean + std in combination with the larger support grid (four times the electrode spacing) or the maximum parameter in combination with support grids of the order of one or two times the electrode spacing allows improving the accuracies of the tests for both cases to a level which might be adequate for engineers dealing with the design of planned actions.

Table 6 shows the results of performance tests conducted on the CPT depth to bedrock model for Hyp. B. MCC values of these tests range from 0.73 (for the first three support grids) to 0.87 (for the last two support grids), meaning that the tests are highly significant to very highly significant. Test accuracies range from $88 \%$ to $94 \%$ and $F_{\beta}$ accuracies are greater than $83 \%$ for both cases studied. Unlike tests conducted on Hyp. A, these tests show that using the depth to bedrock model computed from CPT data allows designing adequate 

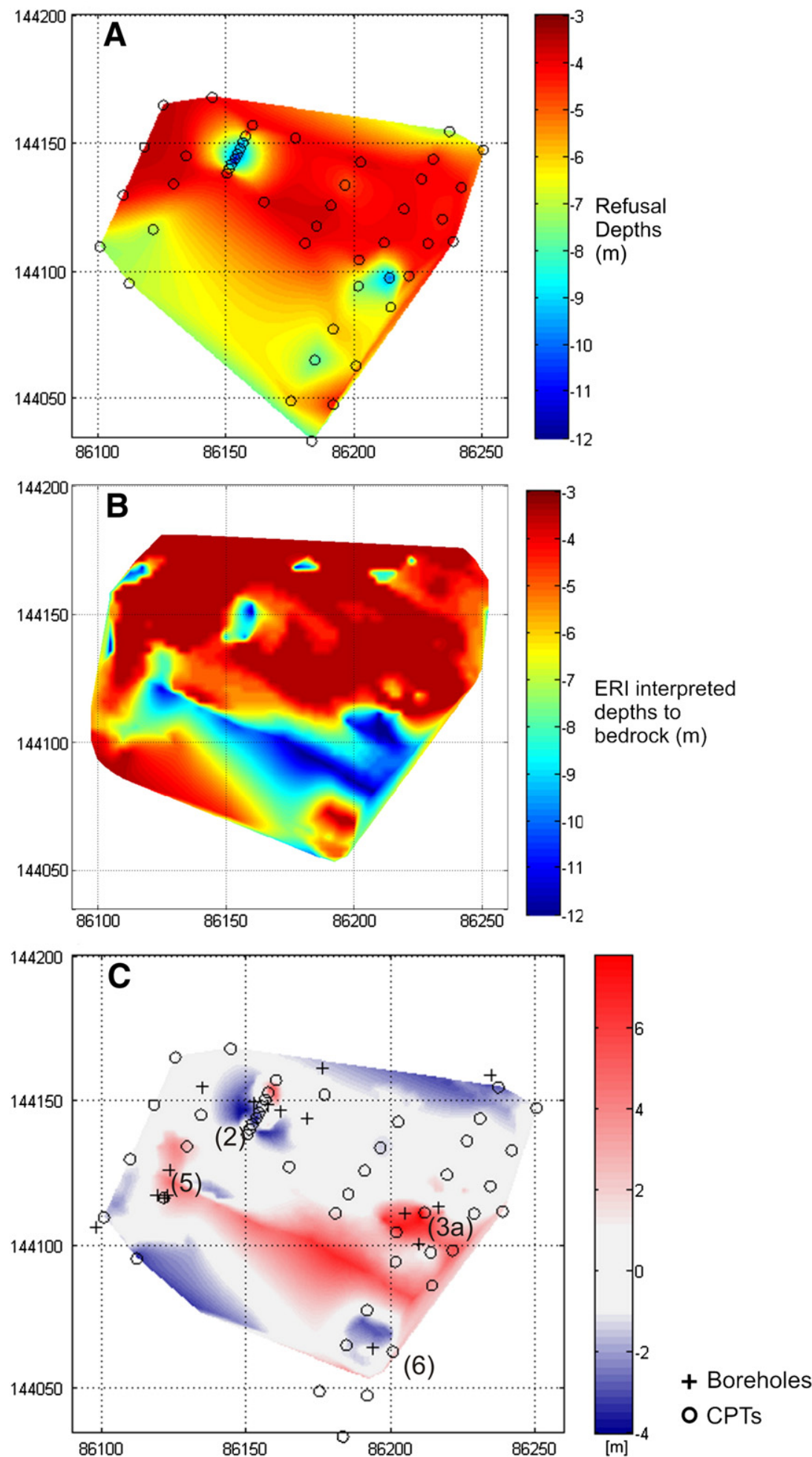

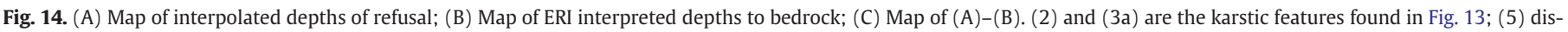
crepancy in depths pointing out that small karst features may be missed using point data; (6) discrepancy in depths linked to a small interpolation artefact.

actions in covered palaeokarst context for Hyp. B. However, since boreholes were drilled near CPT locations, these results are biased and, therefore, have to be looked at with caution.

\subsection{Conclusions of performance tests}

On this site, the depth to bedrock model computed from CPT data reveals highly reliable or completely unreliable to design adequate site-scaled projects depending on the hypothesis tested, even if boreholes were drilled near CPT locations. Therefore, the use of geotechnical investigations, such as CPTs, alone to plan engineering projects over covered palaeokarst is not recommended, especially when karstic features are deeper than a few metres.

Performance tests show that the depth to bedrock model computed based on ERI data was at least significantly reliable for the two hypothesis tested. To construct this model, CPTs were required to 
Table 1

Confusion matrix; Support: volume considered to compute statistical parameters; MCC: Matthews Correlation Coefficient; $F_{0.5}$ and $F_{2}$ are measures of the accuracies of the test for each case studied; TP: true positive; FP: false positive; FN: false negative; TN: true negative.

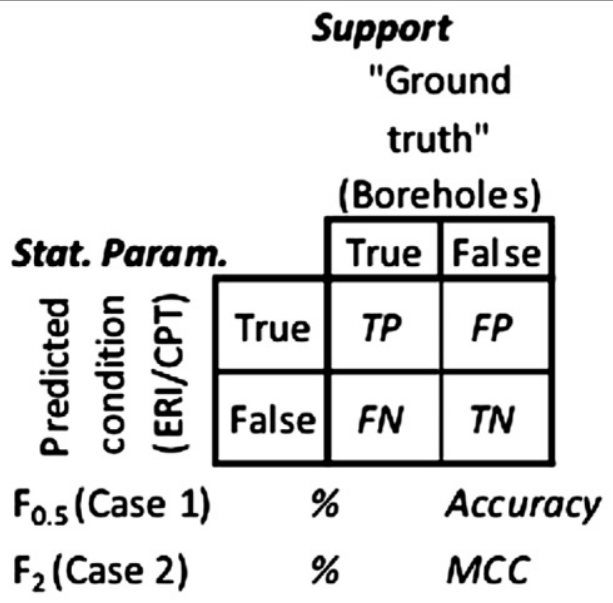

Table 2

MCC thresholds indicating the significance of the tests performed.

\begin{tabular}{llll}
\hline & Significant & Highly significant & Very highly significant \\
\hline$P$ value $(\alpha)$ & 0.05 & 0.01 & 0.001 \\
$\chi^{2}(1$ degree of freedom $)$ & 3.84 & 6.64 & 10.83 \\
$N$ & 16 & 16 & 16 \\
MCC value & 0.49 & 0.64 & 0.82 \\
\hline
\end{tabular}

compute a site-specific resistivity relationship, which allows discrimination between sound rock and weathered material. The mean + std and maximum parameters used in combination with support grids of the order of 1 to 4 times the electrode spacing used for the ERI investigations gave the best results for both engineering problems tested. As palaeokarst feature geometries are clearly three dimensional, using true 3D resistivity imaging should improve the resolution of the resistivity depth to bedrock model and, therefore, improve the accuracy of the proposed investigation strategy.

\section{Summary, recommendations and discussion}

To assess karst hazards in areas of covered karst, such as encountered in the Tournaisis area, suitable investigation methodologies are needed. At a regional scale, integrated methodologies have recently been developed to manage development in karstic areas from a land-use planning perspective. However, karst hazard is spatially highly variable at a local scale; this is certainly the case in the Tournaisis area. Thus, a reliable knowledge of subsurface conditions is essential when dealing with site development and construction projects in such a geological context. Even if combining electrical resistivity imaging with geotechnical data is not a new concept in itself, the reliability of these techniques used together still has to be assessed in such a geological context.

In this paper, a site-specific ERI based investigation strategy to help engineers dealing with the design of construction projects in such a karstic environment is proposed. The strategy was developed on a well-known and heavily studied site where a number of sinkholes had appeared. Eight 2D resistivity tomographs have been produced for the site as well as 46 static cone penetration tests and 16 boreholes. A 3D resistivity model was computed based on the inverted resistivities. Vertical resistivity profiles were then computed at each CPT location to establish a resistivity relationship to discriminate between sound limestone and weathered rock. This empirical relationship is probably site-specific and mainly depends on the

Table 3

Results of the performance tests conducted on Hyp. A with the ERI depth to bedrock model.

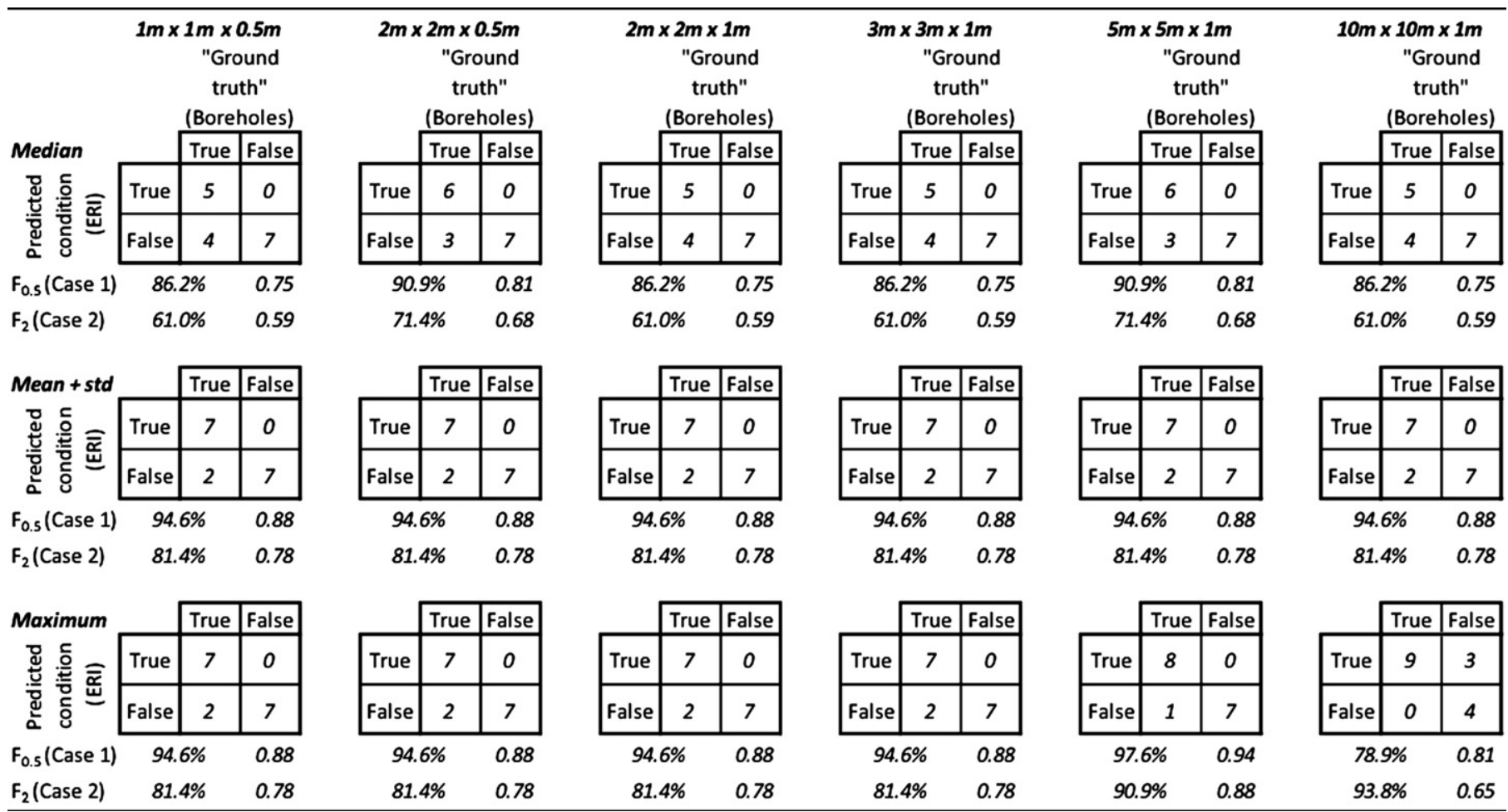


Table 4

Results of the performance tests conducted on Hyp. A with the CPT depth to bedrock model.

\begin{tabular}{|c|c|c|c|c|c|c|c|c|c|c|c|c|c|c|c|}
\hline \multirow[b]{2}{*}{ Hyp A } & \multicolumn{3}{|c|}{$\begin{array}{c}1 m \times 1 m \\
\text { "Ground } \\
\text { truth" } \\
\text { (Boreholes) }\end{array}$} & \multicolumn{3}{|c|}{$\begin{array}{c}2 m \times 2 m \\
\text { "Ground } \\
\text { truth" } \\
\text { (Boreholes) }\end{array}$} & \multicolumn{3}{|c|}{$\begin{array}{c}3 m \times 3 m \\
\text { "Ground } \\
\text { truth" } \\
\text { (Boreholes) }\end{array}$} & \multicolumn{3}{|c|}{$\begin{array}{c}5 m \times 5 m \\
\text { "Ground } \\
\text { truth" } \\
\text { (Boreholes) }\end{array}$} & \multicolumn{3}{|c|}{$\begin{array}{c}10 \mathrm{~m} \times 10 \mathrm{~m} \\
\text { "Ground } \\
\text { truth" } \\
\text { (Boreholes) }\end{array}$} \\
\hline & & True & False & & True & False & & True & False & & True & False & & True & False \\
\hline \multirow{2}{*}{ 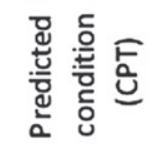 } & True & 9 & 6 & True & 9 & 7 & True & 9 & 7 & True & 9 & 5 & True & 9 & 7 \\
\hline & False & 0 & 1 & False & 0 & 0 & False & 0 & 0 & False & 0 & 2 & False & 0 & 0 \\
\hline $\mathbf{F}_{0.5}$ (Case 1$)$ & \multicolumn{2}{|c|}{$65.2 \%$} & 0.63 & \multicolumn{2}{|c|}{$61.6 \%$} & 0.56 & \multicolumn{2}{|c|}{$61.6 \%$} & 0.56 & \multicolumn{2}{|c|}{$69.2 \%$} & 0.69 & \multicolumn{2}{|c|}{$61.6 \%$} & 0.56 \\
\hline $\mathbf{F}_{2}$ (Case 2) & \multicolumn{2}{|c|}{$88.2 \%$} & 0.29 & \multicolumn{2}{|c|}{$86.5 \%$} & & \multicolumn{2}{|c|}{$86.5 \%$} & & \multicolumn{2}{|c|}{$90.0 \%$} & 0.43 & \multicolumn{2}{|c|}{$86.5 \%$} & \\
\hline
\end{tabular}

geological context and the type of electrical resistivity imaging performed (1D, 2D, 3D, cross-borehole). Comparing resistivities of the model blocks with this empirical relationship finally allows the computation of a 3D depth to bedrock model.

To assess the reliability of this model, performance tests were conducted on two hypotheses by considering two common engineering problems that engineers may encounter when dealing with the design of site-scale projects (deep foundations such as piling and horizontal infrastructure at shallow depth). Three statistical parameters were studied as well as the influence of the width of the support grid. Similar performance tests were also conducted on the depth to bedrock model computed from CPT data. These performance tests show that the ERI-based investigation strategy can, at least significantly, discriminate between sound rock and karst features for both cases studied, while this is not always true for the depth to bedrock model computed from CPT data. Based on these results, it is recommended that, in the Tournaisis area, ERI investigations coupled with several CPT located based on the results of the geophysical investigations be carried out when dealing with site-scale projects in areas with medium or high karstic constraint. Indeed, CPTs are needed in both areas where sound rock is present and where karstic features are located to compute the experimental resistivity relationship.

The cost of the ERI survey was about 75\% of the costs of the geotechnical survey conducted on this site. As some CPTs are needed to implement the strategy developed here, both investigation methodologies should be of the same range of costs. However, the ERI survey allows at least a two dimensional reconstruction of the subsurface and points out suspicious areas where CPTs or boreholes can be carried out to confirm the presence of karstic features. Moreover, to reach the same level of accuracy with a survey conducted with only CPTs, the number of CPTs would increase drastically when planning geotechnical surveys without a priori information on the location of the targets.

However, further investigations are still needed to determine the minimum number of CPT required. This number will probably be dependent on the size of the site investigated and the available budget. A good compromise has to be found between both factors to maximize the reliability of the computed depth to bedrock model.

Table 5

Results of the performance tests conducted on Hyp. B with the ERI depth to bedrock model.

\begin{tabular}{|c|c|c|c|c|c|c|c|c|c|c|c|c|c|c|c|c|c|c|}
\hline \multirow[b]{2}{*}{ Median } & \multicolumn{3}{|c|}{$\begin{array}{c}1 m \times 1 m \times 0.5 m \\
\text { "Ground } \\
\text { truth" } \\
\text { (Boreholes) }\end{array}$} & \multicolumn{3}{|c|}{$\begin{array}{c}2 m \times 2 m \times 0.5 m \\
\text { "Ground } \\
\text { truth" } \\
\text { (Boreholes) }\end{array}$} & \multicolumn{3}{|c|}{$\begin{array}{c}2 m \times 2 m \times 1 m \\
\text { "Ground } \\
\text { truth" } \\
\text { (Boreholes) }\end{array}$} & \multicolumn{3}{|c|}{$\begin{array}{c}3 m \times 3 m \times 1 m \\
\text { "Ground } \\
\text { truth" } \\
\text { (Boreholes) }\end{array}$} & \multicolumn{3}{|c|}{$\begin{array}{c}5 m \times 5 m \times 1 m \\
\text { "Ground } \\
\text { truth" } \\
\text { (Boreholes) }\end{array}$} & \multicolumn{3}{|c|}{$\begin{array}{c}10 m \times 10 m \times 1 m \\
\text { "Ground } \\
\text { truth" } \\
\text { (Boreholes) }\end{array}$} \\
\hline & & True & False & & True & False & & True & \begin{tabular}{|l|} 
False \\
\end{tabular} & & \begin{tabular}{|l|} 
True \\
\end{tabular} & False & & True & False & & True & \begin{tabular}{|l|} 
False \\
\end{tabular} \\
\hline \multirow{2}{*}{ 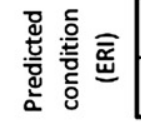 } & True & 2 & 0 & True & 2 & 0 & True & 2 & 0 & True & 2 & 0 & True & 2 & 0 & True & 2 & 0 \\
\hline & False & 4 & 10 & False & 4 & 10 & False & 4 & 10 & False & 4 & 10 & False & 4 & 10 & False & 4 & 10 \\
\hline $\mathbf{F}_{0.5}$ (Case 1) & \multicolumn{2}{|c|}{$71.4 \%$} & 0.75 & \multicolumn{2}{|c|}{$71.4 \%$} & 0.75 & \multicolumn{2}{|c|}{$71.4 \%$} & 0.75 & \multicolumn{2}{|c|}{$71.4 \%$} & 0.75 & \multicolumn{2}{|c|}{$71.4 \%$} & 0.75 & \multicolumn{2}{|c|}{$71.4 \%$} & 0.75 \\
\hline $\mathbf{F}_{2}$ (Case 2) & \multicolumn{2}{|c|}{$38.5 \%$} & 0.49 & \multicolumn{2}{|c|}{$38.5 \%$} & 0.49 & \multicolumn{2}{|c|}{$38.5 \%$} & 0.49 & \multicolumn{2}{|c|}{$38.5 \%$} & 0.49 & \multicolumn{2}{|c|}{$38.5 \%$} & 0.49 & \multicolumn{2}{|c|}{$38.5 \%$} & 0.49 \\
\hline \multirow{3}{*}{ 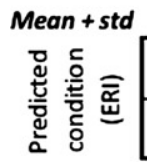 } & & True & False & & True & False & & True & False & & True & False & & True & False & & True & False \\
\hline & True & 2 & 0 & True & 2 & 0 & True & 2 & 0 & True & 2 & 0 & True & 2 & 0 & True & 4 & 0 \\
\hline & False & 4 & 10 & False & 4 & 10 & False & 4 & 10 & False & 4 & 10 & False & 4 & 10 & False & 2 & 10 \\
\hline $\mathbf{F}_{0.5}$ (Case 1$)$ & \multicolumn{2}{|c|}{$71.4 \%$} & 0.75 & \multicolumn{2}{|c|}{$71.4 \%$} & 0.75 & \multicolumn{2}{|c|}{$71.4 \%$} & 0.75 & \multicolumn{2}{|c|}{$71.4 \%$} & 0.75 & \multicolumn{2}{|c|}{$71.4 \%$} & 0.75 & \multicolumn{2}{|c|}{$90.9 \%$} & 0.88 \\
\hline $\mathbf{F}_{2}$ (Case 2) & \multicolumn{2}{|c|}{$38.5 \%$} & 0.49 & \multicolumn{2}{|c|}{$38.5 \%$} & 0.49 & \multicolumn{2}{|c|}{$38.5 \%$} & 0.49 & \multicolumn{2}{|c|}{$38.5 \%$} & 0.49 & 38. & $5 \%$ & 0.49 & 71.4 & $4 \%$ & 0.75 \\
\hline Maximum & & True & False & & \begin{tabular}{|l} 
True \\
\end{tabular} & False & & True & False & & True & False & & \begin{tabular}{|l|} 
True \\
\end{tabular} & False & & \begin{tabular}{|l} 
True \\
\end{tabular} & False \\
\hline 홇 을 $\overline{\bar{\alpha}}$ & True & 2 & 0 & True & 2 & 0 & True & 2 & 0 & True & 3 & 0 & True & 4 & 1 & True & 4 & 2 \\
\hline 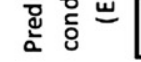 & False & 4 & 10 & False & 4 & 10 & False & 4 & 10 & False & 3 & 10 & False & 2 & 9 & False & 2 & 8 \\
\hline$F_{0.5}$ (Case 1$)$ & 71.4 & $4 \%$ & 0.75 & 71. & $4 \%$ & 0.75 & 71. & $4 \%$ & 0.75 & 83. & $3 \%$ & 0.81 & 76. & $9 \%$ & 0.81 & 66.7 & $7 \%$ & 0.75 \\
\hline $\mathbf{F}_{2}$ (Case 2 ) & 38.5 & $5 \%$ & 0.49 & 38. & $5 \%$ & 0.49 & 38. & $5 \%$ & 0.49 & 55. & $6 \%$ & 0.62 & 69. & $0 \%$ & 0.59 & 66.7 & $7 \%$ & 0.47 \\
\hline
\end{tabular}


Table 6

Results of the performance tests conducted on Hyp. B with the CPT depth to bedrock model.

\begin{tabular}{|c|c|c|c|c|c|c|c|c|c|c|c|c|c|c|c|}
\hline \multirow[b]{2}{*}{ Hyp B } & \multicolumn{3}{|c|}{$\begin{array}{l}1 m \times 1 m \\
\text { "Ground } \\
\text { truth" } \\
\text { (Boreholes) }\end{array}$} & \multicolumn{3}{|c|}{$\begin{array}{l}2 m \times 2 m \\
\text { "Ground } \\
\text { truth" } \\
\text { (Boreholes) }\end{array}$} & \multicolumn{3}{|c|}{$\begin{array}{c}3 m \times 3 m \\
\text { "Ground } \\
\text { truth" } \\
\text { (Boreholes) }\end{array}$} & \multicolumn{3}{|c|}{$\begin{array}{l}5 m \times 5 m \\
\text { "Ground } \\
\text { truth" } \\
\text { (Boreholes) }\end{array}$} & \multicolumn{3}{|c|}{$\begin{array}{c}10 \mathrm{~m} \times 10 \mathrm{~m} \\
\text { "Ground } \\
\text { truth" } \\
\text { (Boreholes) }\end{array}$} \\
\hline & & True & False & & True & False & & True & False & & True & False & & True & False \\
\hline \multirow{2}{*}{ 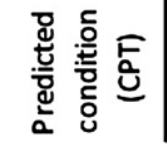 } & True & 5 & 1 & True & 5 & 1 & True & 5 & 1 & True & 5 & 0 & True & 5 & 0 \\
\hline & False & 1 & 9 & False & 1 & 9 & False & 1 & 9 & False & 1 & 10 & False & 1 & 10 \\
\hline$F_{0.5}$ (Case 1) & \multicolumn{2}{|c|}{$83.3 \%$} & 0.88 & \multicolumn{2}{|c|}{$83.3 \%$} & 0.88 & \multicolumn{2}{|c|}{$83.3 \%$} & 0.88 & \multicolumn{2}{|c|}{$96.2 \%$} & 0.94 & \multicolumn{2}{|c|}{$96.2 \%$} & 0.94 \\
\hline $\mathbf{F}_{2}$ (Case 2) & \multicolumn{2}{|c|}{$83.3 \%$} & 0.73 & \multicolumn{2}{|c|}{$83.3 \%$} & 0.73 & \multicolumn{2}{|c|}{$83.3 \%$} & 0.73 & \multicolumn{2}{|c|}{$86.2 \%$} & 0.87 & \multicolumn{2}{|c|}{$86.2 \%$} & 0.87 \\
\hline
\end{tabular}

Based on this experiment, it is recommended that the mean + std or maximum parameters should be used in combination with support grids of 1 to 4 times the electrode spacing to compute the ERI-based depth to bedrock model. When looking at different targets, such as voids or cavities, or in different geological contexts, the parameters used might be modified regarding contrasts in resistivities between targets and bedrock.

As shown in this study, the accuracy of the proposed investigation strategy depends on the engineering problem considered and on the hypotheses tested. Therefore, further research on several additional sites and considering different engineering problems and test hypotheses are needed to fully assess the reliability of this investigation strategy.

\section{Acknowledgements}

The authors wish to thank C. Barcella from the GREN a.s.b.l. for his valuable help during the geophysical measurements. The geophysical investigations were conducted under the auspices of the Faculty of Engineering of Mons (Fonds Special de la Recherche) and the Walloon Region Ministry (visa 95/52278).

\section{References}

Abu-Shariah, M.I.I., 2009. Determination of cave geometry by using a geoelectrical resistivity inverse model. Engineering Geology 105, 239-244.

Aizebeokhai, A.P., 2010. 2D and 3D geoelectrical resistivity imaging: theory and field design. Scientific Research and Essays 5 (23), 3592-3605.

Al-fares, W., Bakalowicz, M., Guérin, R., Duckam, M., 2002. Analysis of the karst aquifer by means of a ground penetrating radar (GPR): example of the Lamalou area (Hérault, France). Journal of Applied Geophysics 51 (2-4), 97-106.

Benson, R.C., Yuhr, L., Kaufmann, R.D., 2003. Assessing the risk of karst subsidence and collapse. American Society Civil Engineers Geotechnical Special Publication 122, 31-39.

Beres, M., Luetscher, M., Olivier, R., 2001. Integration of ground penetrating radar and microgravimetric methods to map shallow caves. Journal of Applied Geophysics 46, 249-262.

Bishop, I., Styles, P., Emsley, S.J., Ferguson, N.S., 1997. The detection of cavities using the microgravity technique: case histories from mining and karstic environments. Geological Society of London. Engineering Geology Special Publication 12 $153-166$.

Buchignani, V., D'Amato, Avanzi G., Giannecchini, R., Puccinelli, A., 2008. Evaporite karst and sinkholes: a synthesis on the case of Camaiore (Italy). Environmental Geology 53, 1037-1044.

Buttrick, D.B., van Schalkwyk, A., 1998. Cases and solutions: Hazard and risk assessment for sinkhole formation on dolomite land in South Africa. Environmental Geology 36 (1), 170-178.

Caramanna, G., Ciotoli, G., Nisio, S., 2008. A review of natural sinkhole phenomena in Italian plain areas. Natural Hazards 45, 145-172.

Cook, J.C., 1965. Seismic mapping of underground cavities using reflection amplitudes. Geophysics 30 (4), 527-538.

Cooper, A.H., 2008. The GIS approach to evaporite-karst geohazards in Great Britain. Environmental Geology 53, 981-992.

Dahlin, T., Zhou, B., 2004. A numerical comparison of 2D resistivity imaging with 10 electrode arrays. Geophysical Prospecting 52, 379-398.
Deceuster, J., Delgranche, J., Kaufmann, O., 2006. 2D cross-borehole resistivity tomographies below foundations as a tool to design proper remedial actions in covered karst. Journal of Applied Geophysics 60, 68-86.

Delvigne, J.E., 1998. Atlas of micromorphology of mineral alteration and weathering The Canadian Mineralogist, Special Publication, ORSTOM Editions, France. . 494 pp.

Dougherty, P., 2005. Sinkhole Destruction of Corporate Plaza Pennsylvania. Case study. In: Waltham, T., Bell, F., Culshaw, M. (Eds.), Sinkholes and subsidence - karst and cavernous rocks in engineering and construction. Praxis, Chichester U.K, pp. 304-308.

Edmonds, C.N., Green, C.P., Higginbottom, I.E., 1987. Subsidence hazard prediction for limestone terrains. Bulletin of the Association of Engineering Geologists 3, 15-25.

Galve, J.P., Gutiérrez, F., Remondo, J., Bonachea, J., Lucha, P., Cendrero, A. 2009. Evaluating and comparing methods of sinkhole susceptibility mapping in the Ebro Valley evaporite karst (NE Spain). Geomorphology 111, 160-172.

Gautam, P., Pant, S.R., Ando, H., 2000. Mapping of subsurface karst structure with gamma ray and electrical resistivity profiles: a case study from Pokhara valley, central Nepal. Journal of Applied Geophysics 45, 97-110.

Gelis, C., Leparoux, D., Virieux, J., Bitri, A., Operto, S., Grandjean, G., 2005. Numerical modeling of surface waves over shallow cavities. Journal of Environmental and Engineering Geophysics 10 (2), 111-121.

Gibson, P.J., Lyle, P., George, D.M., 2004. Application of resistivity and magnetometry geophysical techniques for near-surface investigations in karstic terranes in Ireland. Journal of Cave and Karst Studies 66 (2), 35-38.

Grandjean, G., Leparoux, D., 2004. The potential of seismic methods for detecting cavities and buried objects: experimentations at a test site. Journal of Applied Geophysics 56, 93-106.

Guérin, R., Benderitter, Y., 1995. Shallow karst exploration using MT-VLF and DC resistivity methods. Geophysical Prospecting 43 (5), 635-653.

Hennebert, M., 1998. L'anticlinal faillé du Mélantois-Tournaisis fait partie d'une "structure en fleur positive » tardi-varisque. Annales de la Société Géologique du Nord 6 (2), 65-78.

Hennebert M., Doremus P., 1997. Notice explicative de la Carte Gégologique de Wallonie (1/25.000) - Planche 37/5-6 Hertain-Tournai. Ministère de la Région Wallonne, 63 pp.

Kaufmann, O., 2000. Les effondrements karstiques du Tournaisis: genèse, évolution, localisation, prévention. Speleochronos, Hors-Série. 350 pp.

Kaufmann, O., Deceuster, J., 2005. Ground investigation in covered karst near Tournai, Belgium. Case study. In: Waltham, T., Bell, F., Culshaw, M. (Eds.), Sinkholes and subsidence-karst and cavernous rocks in engineering and construction. Praxis, Chichester U.K, pp. 347-350.

Kaufmann, O., Quinif, Y., 1999. Cover-collapse sinkholes in the "Tournaisis" area, southern Belgium. Engineering Geology 52, 15-22.

Kaufmann, O., Quinif, Y., 2001. An application of cone penetration tests and combined array 2D electrical resistivity tomography to delineate cover-collapse sinkholes prone areas. In: Beck, B.F., Herring, J.G. (Eds.), Geotechnical and Environmental Applications of Karst Geology and Hydrology. Balkema, Lisse, pp. 359-364.

Kaufmann, O., Quinif, Y., 2002. Geohazard map of cover-collapse sinkholes in the Tournaisis area, southern Belgium. Engineering Geology 65, 117-124.

Kaufmann, O., Bini, A., Tognini, P., Quinif, Y., 1999. Etude microscopique d'une altérite de type fantôme de roche. Karst 99 European Conference, France, pp. 129-133.

Loke, M.H., Barker, R.D., 1996a. Rapid least-squares inversion of apparent resistivity pseudosections by quasi-Newton method. Geophysical Prospecting 44, 131-152.

Loke, M.H., Barker, R.D., 1996b. Practical techniques for 3D resistivity surveys and data inversion. Geophysical Prospecting 44, 499-523.

Mansy, J.L., Everaerts, M., De Vos, W., 1999. Structural analysis of the adjacent Acadian and Variscan fold belts in Belgium and northern France from geophysical and geological evidence. Tectonophysics 309, 99-116.

Matthews, B.W., 1975. Comparison of the predicted and observed secondary structure of T4 phage lysozyme. Biochimica et Biophysica Acta 405, 442-451.

Mochales, T., Pueyo, E.L., Casas, A.M., Soriano, M.A., 2007. Magnetic prospection as an efficient tool for doline detection. A case study in the Central Ebro Basin (Northern Spain). In: Parise, M. (Ed.), Geological Society of London. Special Publications: natural and anthropogenic hazards in karst: recognition, analysis and mitigation. 
Mochales, T., Casas, A.M., Pueyo, E.L., Pueyo, Ó., Román, M.T., Pocoví, A., Soriano, M.A., Ansón, D., 2008. Detection of underground cavities by combining gravity, magnetic and ground penetrating radar: a case study from the Zaragoza area, NE Spain. Environmental Geology 53 (5), 1067-1077.

Pearson, K., 1904. On the theory of contingency and its relation to association and normal correlation. Draper's Company Research Memoirs, Biometric series I.

Pueyo-Anchuela, O., Casas-Sainz, A.M., Soriano, M.A., Pocoví-Juan, A., 2010. A geophysical survey routine for the detection of doline areas in the surroundings of Zaragoza (NE Spain). Engineering Geology 114, 382-396.

Quinif, Y., 2010. Fantômes de roche et fantômisation-Essai sur un nouveau paradigme en karstogenèse. Karstologia Mémoires 18196 pp.

Quinif, Y., Rorive, A., 1990. Nouvelles données sur le karst du Tournaisis. Bulletin de la Société Belge de Géologie T. 99 (3-4), 361-372.

Quinif, Y., Bouko, Ph., Cantallina, R., Drumel, P., Rorive, A., 1985. Découverte d'un réseau karstique superficiel à Gaurain-Ramecroix (Hainaut occidental, Belgique) à la faveur de nouveaux puits naturels. Bulletin de la Société Belge de Géologie T. 94 (1), 45-50.

Reynolds, J.M., 2011. An Introduction to Applied and Environmental Geophysics, Second edition. Wiley-Blackwell, John Wiley and Sons, ltd, Chichester, UK

Roth, M.J.S., Mackey, J.R., Mackey, C., Nyquist, J.E., 2002. A case study of the reliability of multielectrode earth resistivity testing for geotechnical investigations in karst terrains. Engineering Geology 65, 225-232.

Rybakov, M., Goldshmidt, V., Fleischer, L., Rotstein, Y., 2001. Cave detection and 4-D monitoring: a microgravity case history near the Dead Sea. Leading Edge 20 (8), 896-900.

Rybakov, M., Rotstein, Y., Shirman, B., Al-Zoubi, A., 2005. Cave detection near the Dead Sea-a micromagnetic feasibility study. The Leading Edge (Society of Exploration Geophysicists) 24 (6), 585-590.
Sowers, G.F., 1996. Building on sinkholes: design and construction of foundations in karst terrain. ASCE Press. 202 pp.

Sumanovac, F., Weisser, M., 2001. Evaluation of resistivity and seismic methods for hydrogeological mapping in karst terrains. Journal of Applied Geophysics 47, 13-28.

Thierry, P., Debeblia, N., Bitri, A., 2005. Geophysical and geological characterisation of karst hazards in urban environments: application to Orléans (France). Bulletin of Engineering Geology and the Environment 64, 139-150.

Thomas, B., Roth, M.S., 1999. Evaluation of site characterization methods for sinkholes in Pennsylvania and New Jersey. Engineering Geology 52, 147-152.

Van Rantergem, G., Bouckaert, P., Quinif, Y., 1993. Une nouvelle grotte à GaurainRamecroix. Bulletin de la Société Belge de Géologie T. 102 (3-4), 395-399.

van Rijsbergen, C.J., 1979. Information Retrieval, 2nd ed. Butterworth.

Van Schoor, M., 2002. Detection of sinkholes using 2D electrical resistivity imaging. Journal of Applied Geophysics 50, 393-399.

Waltham, T., Bell, F., Culshaw, M., 2005. Sinkholes and Subsidence-Karst and Cavernous Rocks in Engineering and Construction. Praxis, Chichester U.K.. 382 pp.

Xia, J., Nyquist, J.E., Xu, Y., Roth, M.J.S., Miller, R.D., 2007. Feasibility of detecting nearsurface feature with Rayleigh-wave diffraction. Journal of Applied Geophysics 62, 244-253.

Yuan, D., Li, B., Liu, Z., 1998. Karst of China. In: Yuan, D., Liu, Z. (Eds.), Global Karst Correlation. Science Press, Beijing, pp. 167-177.

Zhou, W., Beck, B.F., Adams, A.L., 2002. Effective electrode array in mapping karst hazards in electrical resistivity tomography. Environmental Geology 42, 922-928. 